\title{
Bhutan: Poverty Reduction Strategy Paper
}

Poverty Reduction Strategy Papers (PRSPs) are prepared by member countries in broad consultation with stakeholders and development partners, including the staffs of the World Bank and the IMF. Updated every three years with annual progress reports, they describe the country's macroeconomic, structural, and social policies in support of growth and poverty reduction, as well as associated external financing needs and major sources of financing. This country document for Bhutan, dated 2004, is being made available on the IMF website by agreement with the member country as a service to users of the IMF website.

To assist the IMF in evaluating the publication policy, reader comments are invited and may be sent by e-mail to publicationpolicy@imf.org.

Copies of this report are available to the public from

International Monetary Fund • Publication Services

$70019^{\text {th }}$ Street, N.W. • Washington, D.C. 20431

Telephone: (202) 623-7430 • Telefax: (202) 623-7201

E-mail: publications@imf.org・Internet: http://www.imf.org

Price: $\$ 15.00$ a copy

\section{International Monetary Fund \\ Washington, D.C.}




\section{Poverty Reduction Strategy Paper}

\section{A Cover Note to the Ninth Plan Main Document}

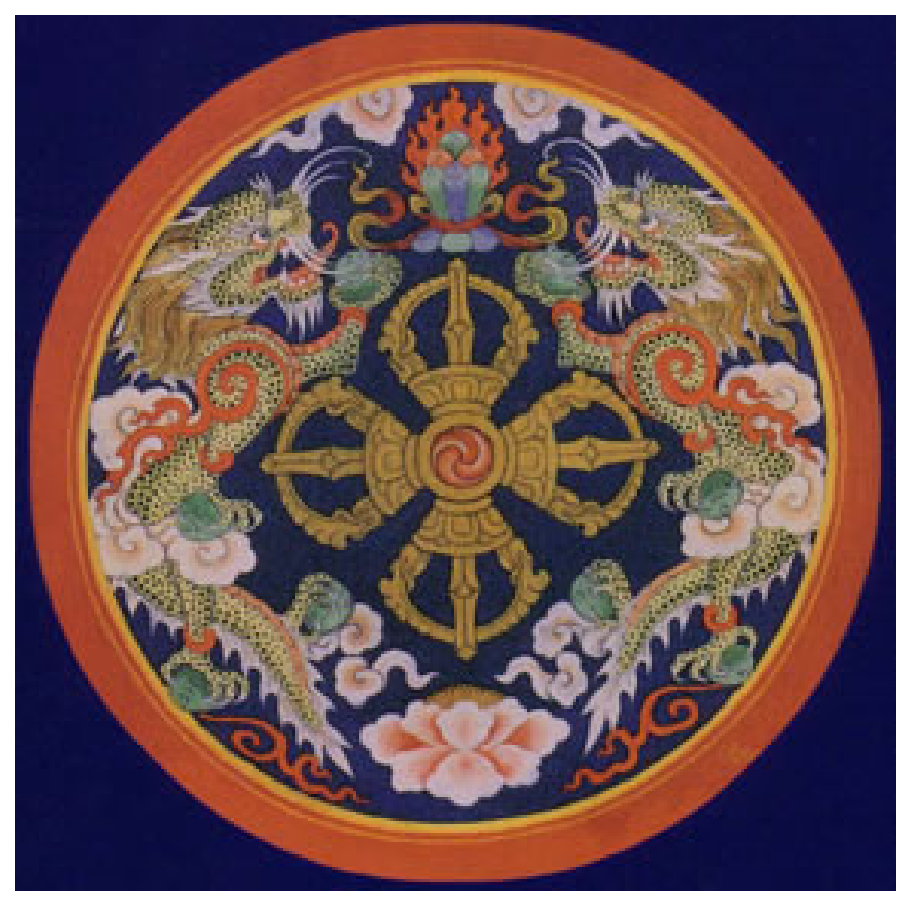

Department of Planning

Ministry of Finance

Royal Government of Bhutan

2004 


\section{TABLE OF CONTENTS}

EXECUTIVE SUMMARY .................................................................................. 3

1. INTRODUCTION - POVERTY REDUCTION STRATEGY PAPER ............. 5

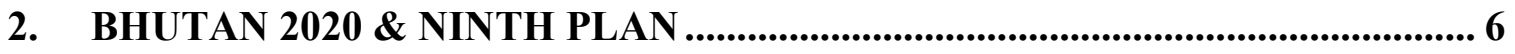

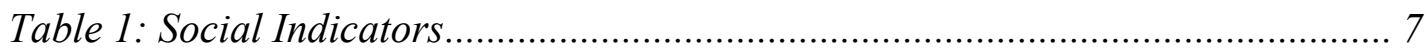

3. RECENT ECONOMIC \& POLICY DEVELOPMENTS AND THE OUTLOOK ................................................................................................ 10

4. MEDIUM TERM EXPENDITURE FRAMEWORK (MTEF)......................... 14

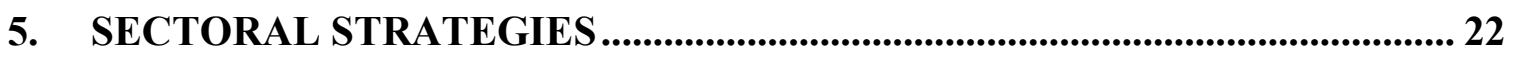

Table 4: Sectoral Allocations as laid out in the Ninth Plan .................................. 23

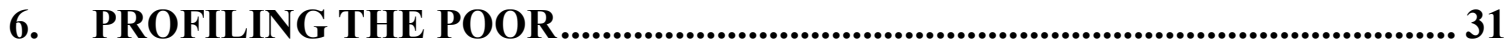

7. POVERTY REDUCTION CHALLENGES AND STRATEGIES .................... 36

8. POVERTY MONITORING AND ASSESSMENT ....................................... 40

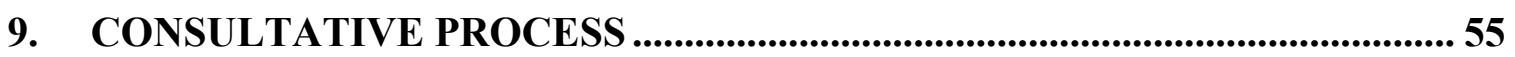




\section{List of Acronyms}

BPMAS Bhutan Poverty Monitoring and Assessment System

DYT

GYT

MDGs

$M \& E$

MTEF

DoP Dzongkhag Yargye Tshogdue/District Development Committee

PMU Gewog Yargye Tshogchung/Block Development Committee Millennium Development Goals

PRSP Monitoring and Evaluation

Medium Term Expenditure Framework Department of Planning

PVI

Poverty Monitoring Unit

PIN

Poverty Reduction Strategy Paper

RGoB

Poverty Vulnerability Indicators

RNR

Planning Information Network

Royal Government of Bhutan

Renewable Natural Resource 


\section{Executive Summary}

1. The Royal Government of Bhutan (RGoB) has initiated a Poverty Reduction Strategy Paper (PRSP) process as a part of the broader ongoing efforts to combat poverty. The main objective of the PRSP process is to strengthen the strategic framework for poverty reduction, improve donor coordination, and build support for new initiatives in public expenditure management and poverty monitoring and evaluation. The envisaged process builds directly on the Ninth Five-Year Plan (Ninth Plan), and this Cover Note together with the Ninth Plan document will comprise the PRSP.

2. As an extension of the Ninth Plan, this Cover Note elaborates on several key areas and has 9 parts. Part I introduces the PRSP process envisaged in Bhutan. Part II briefly presents the country background, Bhutan 2020 - Vision for Peace, Prosperity and Happiness, and the main objectives and strategies of the Ninth Plan. Part III discusses recent economic and policy developments and the outlook. Part IV presents a medium term expenditure framework (MTEF). Part V discusses the sectoral strategies. Part VI highlights the profiling of poor such as who are the poor, where are they located and causes of poverty. Part VII enumerates on poverty reduction challenges and strategies. Part VIII describes ongoing efforts to strengthen the poverty monitoring and evaluation system as laid out in the proposed Bhutan Poverty Monitoring and Assessment System (PMAS) report. Part IX elaborates on the consultative process that underpinned the preparation of the Ninth Plan and that is envisaged for the PRSP. More details on the macroeconomic, structural and social policies, and the sectoral objectives, strategies and programs are discussed in the main document of the Ninth Plan.

3. Bhutan's development is guided by the philosophy of Gross National Happiness emphasizing a balance between material well-being and the spiritual, emotional and cultural well-being of an individual and the society. The long-term vision of where Bhutan wants to be in the next two decades is laid down in the Bhutan 2020 document. These long-term visions are translated into concrete sectoral policies, strategies and programs in the five-year development plans. The current Ninth Plan, which runs from July 2002 to June 2007, accords high priority to infrastructure development and improving the quality of social services.

4. With strong levels of growth and record low inflation, Bhutan continues to enjoy a stable macroeconomic environment conducive to sustained growth. As of December 2003, growth was about 6.5 percent with the major impetus coming from the construction, manufacturing and transportation sectors. The consumer price index recorded further decrease in inflation to a historical low of $1.3 \%$ as of December 2003. With inflows of foreign aid, concessional loans and some foreign investment offsetting the persistent trade deficit, Bhutan has accumulated foreign reserves amounting to the equivalent of USD 366.71 million by December 2003, which is an increase of around 16 percent over the reserves of USD 316.9 
million in June $2002^{1}$. This reserve is sufficient to cover around 22 months of imports. These trends are expected to continue in the coming years. Government expenditure in $2002 / 2003$ is estimated to have been only slightly larger than budgeted, but the overall fiscal deficit rose to about 9 percent of GDP, mainly because external grants received were smaller than anticipated. With an increase in grants, the approved budget for 2003/2004 projects narrowing of the overall fiscal balance to about 4 percent of GDP.

5. In an effort to strengthen the budget process and the management of public expenditures, the RGoB has initiated a two-year rolling budget mechanism. As a part of these endeavors, some of the key features of an MTEF are developed in this cover note. Based on estimates of recent economic developments and the outlook, the MTEF covering the next three years anticipates budget deficits between 3 and 4 percent of GDP, and overall spending between 35 and 40 percent of GDP. Public spending continues to focus on poverty reduction and economic growth, emphasizing infrastructure (11 percent of the budget for roads) and social services (about 24 percent for health and education).

6. In order to facilitate focusing of policies and adopting of appropriate strategies in addressing poverty, the analyzing of poverty incidences through, such as, profiling of poor would give a meaningful input. With this objective in mind, the Royal Government attempted carrying out some poverty studies such as Household Income and Expenditure Survey 2000 (HIES 2000) and Poverty Assessment and Analysis 2000 (PAA 2000) on pilot basis. While the HIES 2000 findings focused on the household level, the PAA 2000 results dealt with the situation at the block (Gewog) and district (Dzongkhag) levels. They complement each other. However, as is often the case with any surveys of this nature, the results should be taken as indicative until they are confirmed through more systematic surveys.

7. Monitoring and evaluation have always been a high priority, and efforts to streamline and institutionalize the system are underway. A draft Poverty Monitoring and Assessment System (PMAS), which aims to facilitate the coordinated and systematic use of data for impact assessment, is being worked out internally and is likely to be finalized as soon as the list of poverty indicators is finalized.

8. The consultative process for the Ninth Plan brought together various stakeholders including the central ministries and agencies, Dzongkhag and Gewogs, and donors. It was carried out over a 2 year time period, and also underpins the PRSP process. Several key sectoral ministries are involved in the drafting of this Cover Note, in the sense that concerned sectors were consulted while preparing it with technical assistance from the World Bank.

\footnotetext{
${ }^{1}$ RMA Monthly Statistical Bulletin, Vol. II. No. 7, July 2003
} 


\section{Introduction - Poverty Reduction Strategy Paper}

1.1 The Royal Government of Bhutan (RGoB) has initiated a Poverty Reduction Strategy Paper (PRSP) process as a part of the broader ongoing efforts to combat poverty. The main objective of the PRSP is to strengthen the strategic framework for poverty reduction, improve donor coordination, and build support for new initiatives in public expenditure management (annual plans and two year rolling budget introduced from financial year 2003-04) and poverty monitoring and assessment system (PMAS).

1.2 The PRSP seeks to complement the Ninth Plan main document by:

a) Presenting a brief update on recent economic developments over the first year of the plan;

b) Elaborating an MTEF;

c) Highlighting on profiling of the poor and causes of poverty;

d) Enumerating on poverty reduction challenges and strategies;

e) Describing the proposed poverty monitoring and assessment system,

f) Discussing the consultative process of both the Ninth Plan and that envisaged for the PRSP.

\section{Institutional Arrangements}

1.3 The Department of Planning (DoP), under the Ministry of Finance, is the lead agency in preparing the PRSP. The DoP was identified as the lead PRSP agency in view of its role in coordinating, formulating, implementing and monitoring poverty related programs. The DoP also facilitates consultation and consensus building regarding pro-poor policy across a broad range of stakeholders.

1.4 To improve information flow and coordinate existing monitoring systems, the DoP works closely with National Statistical Bureau (NSB), Planning \& Policy Division (PPD) in the ministries, and the Dzongkhag technical units, especially Planning Unit. In view of the high priority being accorded to the poverty issues, the Department of Planning is in the process of considering the establishment of a Poverty Monitoring Unit (PMU) within the DoP to assess Poverty Vulnerability Indicators (PVI), outcome monitoring, impact assessment and to perform the crucial function of communication and advocacy on poverty. In case the PMU is established, it will be responsible for key aspects of the PRSP, including the submission of poverty progress reports to the concerned authorities for review.

1.5 The PRSP has been prepared in consultation with all concerned sectors and agencies. 


\section{Bhutan 2020 \& Ninth Plan}

2.1 Bhutan is a small land locked country in Eastern Himalayas bordered by India in the south and China in the north. It has one of the most formidable mountainous terrains in the world, ranging from 100 meters to 7,500 meters in height. Bhutan has a land area of 38,394 square kilometers with about 72 percent forest coverage. The estimated population is $734,340(2003)^{1}$ with 79 percent rural population and about 42 percent of the population below the age of 15 .

2.2 Administratively, the country is divided into 20 Dzongkhags (districts), which are further sub-divided into 201 Gewogs (Blocks). The Dzongkhag Yargye Tshogdue (DYT) or the District Development Committee, and the Gewog Yargye Tshogchungs (GYT) or the Block Development Committee, are the two main institutions for local decision-making and plan implementation. The members of these committees are the elected representatives of the people.

\section{Bhutan 2020: A Vision for Peace, Prosperity and Happiness}

2.3 Gross National Happiness is the overarching development philosophy of Bhutan. It recognizes the need to balance material well-being with spiritual, emotional and cultural well-being of the individual and the society for a holistic development. Accordingly, four major areas have been identified as pillars of Gross National Happiness and these are a) economic growth and development; b) preservation and promotion of cultural heritage; c) preservation and sustainable use of the environment; and d) good governance.

2.4 Gross National Happiness has been the guiding principle for socio economic development of Bhutan in the last two decades and will continue to be so in the future as envisaged in the document "Bhutan 2020: A Vision for Peace, Prosperity and Happiness".

2.5 Bhutan 2020: A Vision for Peace, Prosperity and Happiness is a twenty year perspective strategy which sets the preferred direction for where Bhutan wants to be in the next two decades. It highlights the national goals, broad targets and overall policy principles for the next twenty years. It is based on the six main principles of a) maintaining a distinct identity; b) strengthening unity and harmony; c) guaranteeing a nationwide stability for peace and prosperity; d) promoting self-reliance; e) pursuing sustainable development and f) demonstrating capacity to effectively respond to challenges and possibilities.

\footnotetext{
${ }^{1}$ Statistical Yearbook of Bhutan, 2003, NSB
} 


\section{Box 1: Bhutan's development path into the new millennium emphasizes:}

1. Human Development as capacity for individuals to make choices within a traditional ethos fundamental to Bhutan's development approach that seeks to improve overall quality of life and respect for human rights such that rights to education, health, and livelihoods complement abstract rights of equality before law.

2. Culture \& Heritage to ensure relevance for a society in transition by becoming an integrating factor of harmony and social cohesiveness based on acquisition of knowledge for communal enrichment and well being, while remaining a source of enabling inspiration for Bhutanese to adjust and cope with the rapid pace of modernization and social transformation.

3. Balanced Equitable Development to ensure equitable development benefits among varying income groups and regions, and drawing into development mainstream marginalized and vulnerable groups with all efforts to strengthen grass roots organization such that people make well-informed decisions on their roles in development.

4. Governance to create effective community participation in making informed decisions through governance architecture that emphasizes "golden yoke of governance" such that closer decisionmaking process reaches communities through institutions and procedures that pursue and manage rule of law, human rights, transparency, accountability, participatory development, and decentralization, as preconditions of human happiness the more operational becomes GNH.

5. Environmental Conservation to embody environmental sustainability such that Bhutan's natural heritage remains a development asset with global significance. Bhutan is internationally acknowledged for contributing to a global environmental agenda by preserving $72 \%$ of land under forest cover strengthened by a policy to refrain from appropriating short-term economic gains at the expense of its pristine environment.

2.6 Bhutan 2020 serves as a milestone for planning and guidance, setting targets such as a) providing electricity to $50 \%$ of the rural population by 2012 ; b) achieving a three fold increase in real income of farmers by 2012 ; c) ensuring that $75 \%$ of the rural population live within half a day's walk from nearest road; and d) maintaining $60 \%$ of Bhutan's land area under forest coverage in perpetuity. The vision set out in Bhutan 2020 is translated into sectoral policies, strategies and programs through five-year development plans. The key social targets for the Ninth Plan, which are consistent with the Bhutan 2020 and the MDGs, are listed in Table 1.

Table 1: Social Indicators

\begin{tabular}{|c|c|c|c|}
\hline Indicator & 1994 & 2000 & Target for 2007 \\
\hline Population growth rate (percent) & 3.1 & 2.5 & 2.3 \\
\hline Primary school gross enrolment rate (percent) & & & \\
\hline Total & & 72 & \\
\hline Boys & & 82 (in 99) & \\
\hline Girls & 67 (in 90) & 62 (in 99) & \\
\hline Adult literacy rate (percent) & 48 & 54 & $\ldots$ \\
\hline Life expectancy at birth (years) & & & \\
\hline Total & 66.1 & 66.1 & \\
\hline Men & 66.0 & 66.0 & \\
\hline Women & 66.2 & 66.2 & \\
\hline Infant mortality (per 1,000 live births) & 70.7 & 60.5 & 30 \\
\hline Under 5 mortality (per 1,000 live births) & 96.9 & 84.0 & 50 \\
\hline Maternal mortality (per 1,000 live births) & 3.80 & 2.55 & 1.50 \\
\hline Low birth weight (less than $2.5 \mathrm{~kg}$ )(percent) & 36.0 & 24.0 & 12.0 \\
\hline Access to clean water (percent) & 57 & 77.8 & 100 \\
\hline
\end{tabular}




\begin{tabular}{|l|r|r|r|}
\hline Access to safe sanitation (percent) & $\ldots$. & 88.0 & 100 \\
\hline Doctors per 10,1000 population & 1.5 & 1.7 & $\ldots$ \\
\hline Trained nurses per 10,000 (percent) & 1.4 & 2.3 & $\ldots$ \\
\hline Births attended by trained personnel (percent) & 10.9 & 23.7 & $\ldots$ \\
\hline Contraceptive prevalence rate (percent) & 18.8 & 30.7 & $\ldots$ \\
\hline
\end{tabular}

\section{Ninth Plan}

2.7 The main document of the Ninth Plan should be referred to for more detail. The cover note only reviews the broad themes and the highlights.

2.8 The Ninth Plan covers the period July 2002 to June 2007. It is different from the past plans in the sense that for the first time it includes individual plans for 201 Gewogs, prepared by the communities and their elected representatives. The communities will be responsible for the implementation and monitoring of the Gewog plans with technical backstopping support from the Dzongkhag and the central agencies.

2.9 The Ninth Plan consists of a) Ninth Plan Main Document; b) Sectoral Plans; c) 20 separate Dzongkhag Plans and d) 201 individual Gewog Plans. The main document pulls these different components together and outlines the broad national policy aims, objectives and strategies over the next five-year period. These broad policies and objectives are translated into detailed strategies and programs in the sectoral, Dzongkhag and Gewog plan documents. The central plan consists of programs that require inter-Dzongkhag coordination, substantial resources and technical expertise. Dzongkhag plans include programs that require inter-Gewog coordination, institutional strengthening and capacity development of their sectoral human resources. Gewogs plans consist mainly of social and rural infrastructure development programs such as construction of farm roads, outreach clinics, community schools, irrigation facilities, suspension bridges, mule tracks, and rural water supply schemes which are within the scope of the technical competency of communities for implementation.

\section{Main objectives}

2.10 The Ninth Plan has five overall objectives namely a) Improving the quality of life and income, especially of the poor; b) Ensuring good governance; c) Promoting private sector growth and employment generation; d) Preserving and promoting cultural heritage and environment conservations; and e) Achieving rapid economic growth and transformation. The objectives are consistent with making progress towards realizing the Millennium Development Goals (MDGs) by 2015, or even earlier.

2.11 The strategies to achieve the above objectives include a) infrastructure expansion; b) sound macro-economic policy; c) ensuring good governance; and d) improving access and enhancing social services. 


\section{Key Strategies}

\section{Strategy I: Infrastructure expansion}

2.12 The Plan accords high priority to infrastructure expansion such as expansion of road network particularly feeder roads to improve rural access, provision of electricity to at least 15,000 rural households, provision of rural telecommunications and urban infrastructure.

\section{Strategy II: Sound Macro-economic policy}

2.13 Appropriate macroeconomic and fiscal policies will be formulated to ensure stable economic growth of 7-9 percent and private sector participation. Continued efforts will be made to increase domestic resources through improved tax administration and the introduction of new taxes to broaden the revenue base.

\section{Strategy III: Ensuring Good Governance}

2.14 Efforts to strengthen good governance would continue through administrative and political reforms and creation of new structures and processes. Most significant will be the adoption of a written national constitution.

\section{Strategy IV: Improving Access and Enhancing Social Services}

2.15 It is observed that communities that are closer to roads are better off in terms of economic and social well being than those further away. Therefore, improving access through infrastructure expansion is a key strategy for poverty reduction, enhancing the quality of social services and increasing economic opportunities.

\section{Financial Framework}

2.16 The total outlay for the Ninth Plan is Nu. 70,000 million, of which Nu. 31,682 million is for current expenditures, Nu. 34,869 million for capital investments and Nu. 3,449 million is for debt servicing. Current expenditure is to be covered by domestic revenue of $\mathrm{Nu}$. 32,000 million, while external assistance amounting to over $\mathrm{Nu}$. 28,000 (earlier estimate was $\mathrm{Nu}$. 35,000 million comprising grant of $\mathrm{Nu}$. 30,000 and loan of $\mathrm{Nu}$. 5,000), out of which approximately $\mathrm{Nu}$. 21,000 million in the form of grant assistance and $\mathrm{Nu} .7,000$ million in concessionary loans is expected to finance capital investments. A budgetary gap of over $\mathrm{Nu}$. 5,000 million is to be covered by domestic borrowing. 


\section{Recent Economic \& Policy Developments and the Outlook}

\section{Growth}

3.1 As per the provisional national accounts data, real GDP grew by $6.5 \%$ in 2003 , slightly lower than the Eighth Plan average of 6.7 percent (Table 2). The major impetus of growth came from construction, manufacturing and transportation sectors each registering growth of 16.4 percent, 14.3 percent and 11.8 percent respectively. Agriculture grew more slowly, but it continues to be the largest sector of the economy, contributing 30 percent of GDP in the first year of the Ninth plan. Construction has been a dynamic source of growth mainly as a result of activities associated with the Kurichhu, Basochhu and Tala hydropower projects.

3.2 Growth during the next three years (2004-05 to 2006-07) is expected to average around 8 percent per annum. The construction, manufacturing, transportation and electricity sectors are expected to be the key sectors spurring growth. Table 2: Ninth Plan Sector-wise GDP Projections 


\begin{tabular}{|c|c|c|c|c|c|c|c|c|c|}
\hline & $\begin{array}{c}8^{\text {th }} \\
\text { Plan } \\
\text { growth } \\
(\%)\end{array}$ & $\begin{array}{c}\% \\
\text { share } \\
\text { of } \\
\text { GDP } \\
\text { in } \\
2000\end{array}$ & 2002/03 & $2003 / 04$ & $2004 / 05$ & $2005 / 06$ & $2006 / 07$ & $\begin{array}{c}9^{\text {th }} \\
\text { FYP } \\
\text { growth } \\
(\%)\end{array}$ & $\begin{array}{c}\% \\
\text { share } \\
\text { to } \\
\text { GDP } \\
\text { at the } \\
\text { end } \\
\text { of } \\
\text { Ninth } \\
\text { Plan }\end{array}$ \\
\hline Agriculture & 2.5 & 34.5 & 1483.0 & 1520.0 & 1558.0 & 1597.0 & 1636.9 & 2.5 & 25.3 \\
\hline $\begin{array}{l}\text { - Crop } \\
\text { Production }\end{array}$ & 2.4 & 27.4 & 750.1 & 768.1 & 786.5 & 805.4 & 824.5 & 2.4 & 12.7 \\
\hline $\begin{array}{l}\text { - Livestock } \\
\text { Production }\end{array}$ & 3 & 7.1 & 307.4 & 316.6 & 326.1 & 335.9 & 345.9 & 3.0 & 5.3 \\
\hline $\begin{array}{l}\text { - Foresty and } \\
\text { logging }\end{array}$ & 2.4 & 10.0 & 429.9 & 440.2 & 450.8 & 461.6 & 472.7 & 2.4 & 7.3 \\
\hline Mining etc & 5.9 & 1.2 & 53.7 & 57.2 & 60.8 & 64.7 & 80.0 & 10.5 & 1.2 \\
\hline Manufacturing & 4.7 & 7.1 & 375.0 & 393.4 & 412.7 & 433.3 & 454.9 & 4.9 & 7.0 \\
\hline Electricity & 9.3 & 9.7 & 598.7 & 676.5 & 764.5 & 863.9 & 949.4 & 12.2 & 14.6 \\
\hline Construction & 16.3 & 11.4 & 629.6 & 732.9 & 853.1 & 993.0 & 1155.9 & 16.4 & 17.8 \\
\hline $\begin{array}{l}\text { Trade and } \\
\text { Commerce }\end{array}$ & 4.5 & 6.0 & 267.6 & 279.7 & 292.3 & 305.4 & 319.1 & 4.5 & 4.9 \\
\hline $\begin{array}{l}\text { Transport \& } \\
\text { Communication }\end{array}$ & 11.4 & 9.8 & 494.8 & 553.2 & 618.5 & 691.5 & 773.1 & 11.8 & 11.9 \\
\hline Finance etc. & 8 & 10.3 & 489.7 & 528.8 & 571.2 & 616.8 & 678.5 & 8.5 & 10.5 \\
\hline $\begin{array}{l}\text { Government } \\
\text { service }\end{array}$ & 4.4 & 10.1 & 448.9 & 472.3 & 496.8 & 522.7 & 555.0 & 5.4 & 8.6 \\
\hline $\begin{array}{ll}\text { Less } & \text { bank } \\
\text { services } & \\
\text { charges } & \\
\end{array}$ & 0.1 & & -118.0 & -118.6 & -119.2 & -119.8 & -120.4 & 0.5 & -1.9 \\
\hline $\begin{array}{l}\begin{array}{l}\text { GDP in } 1980 \\
\text { prices }\end{array} \\
\text {. }\end{array}$ & & & 4723.1 & 5095.5 & 5508.7 & 5968.7 & 6482.5 & 8.2 & 100.0 \\
\hline GDP growth & 6.7 & & 11.0 & 7.9 & 8.1 & 8.3 & 8.6 & & \\
\hline $\begin{array}{l}\text { GDP at current } \\
\text { prices }\end{array}$ & & & 26779.8 & 30878.5 & 35751.3 & 41481.2 & 48165.1 & 15.8 & \\
\hline Deflator & & & 567 & 606 & 649 & 695 & 743 & & \\
\hline
\end{tabular}

\section{Balance of Payments}

3.3 The most recent available data, provisional, covering period up to June 2003, indicate favorable balance of payments with continued inflow of foreign aid, concessional loans and some foreign investment offsetting the persistent trade deficit. Bhutan has accumulated gross foreign reserves amounting to the equivalent of USD 366.71 million by December 2003, sufficient to cover around 22 months of imports. Convertible currency reserves account for USD 288.28 million and balance in Indian rupees. Imports grew at annual average of 20 percent over the last decade compared to 14.5 percent for exports, with total 
imports valued at Nu. 9042.1 million (27\% of GDP, 2003), and total exports value at Nu.5405.9 million (17\% of GDP, 2003). Trade deficit, narrowed slightly to Nu. 3636.2 million in 2002-03. However, strong inflows of aid were more than sufficient to offset this deficit, and a current account surplus of Nu. 2937.1 million ( $9 \%$ of GDP) is estimated for $2002 / 03$.

3.4 The trade deficits is expected to continue during the Ninth Plan, financed by positive inflows of external assistance and growth in foreign direct investment. The commissioning of Tala in 2005/06 will boost electricity exports to India and help to narrow the trade deficit in the later years of the Ninth Plan. India remains the dominant trading partner, but attempts are being made to diversify trade in terms of products and trading partners. The foreign reserves are projected to grow in the coming years.

\section{Debt Outstanding}

3.5 As of December 2003, the stock of external debt outstanding was USD 472.193 million or around 67 percent of GDP. Out of this, convertible currency debt stock accounted for around 41 percent. The entire convertible currency debt stock is concessional in nature with the most favorable terms and conditions. The debt service ratio for the same period was 3.5 percent, reflecting the highly concessional nature of Bhutan's debt portfolio.

3.6 In the coming year, external borrowings are expected to fund $15 \%$ of total government capital outlay. As in the past, concessional loans will be availed for priority investment projects with high economic returns and for which grant financing is not forthcoming.

\section{Monetary policy and Inflation}

3.7 Monetary policy will continue to be aimed at maintaining the Ngultrum-Rupee parity. Though this limits the scope for an independent monetary policy, it contributes to macro economic stability, and facilitates trade with India which accounts for $80 \%$ of Bhutan's external trade. Among others, the Royal Monetary Authority plans to foster competition in the financial sector. The excess liquidity problem has also been reduced considerably over the last year.

3.8 The rate of inflation, as recorded by the consumer price index, decreased further from 2.7 percent at the end of the Eighth Plan to a historical low of 1.3 percent in December 2003 The inflation in India has been relatively low in recent years and since inflation in Bhutan closely tracks the inflation in India, Bhutan's rate of inflation is projected to remain below 4 percent in the coming years. 


\section{Fiscal Policy}

3.9 The RGoB will continue to pursue the policy of financing the recurrent expenditures from domestic revenue and capital investments through external assistance, largely in the form of grant financing. The overall fiscal deficit in 2002-03 reached 11 percent of GDP but the RGoB seeks to limit the overall budgetary deficit to about 4-5 percent of the GDP in the coming years, but will depend largely on the external funding availability. A more detailed discussions on the fiscal performance and the outlook is presented as part of the MTEF below.

\section{Other Developments}

3.10 Foreign Direct Investment (FDI) can be a driving force for rapid economic growth. Foreign investment provides access to capital, markets and new technologies as well as transfer of managerial skills. In addition, FDI is a more stable source of foreign capital. Therefore, even though Bhutan is not an attractive FDI destination given the numerous disadvantages of being a small, landlocked, mountainous country, Bhutan must try to attract as much foreign investment in the areas where we have some advantage. To provide the framework for such investments, the RGoB approved the FDI Policy in December 2002.

3.11 Bhutan acceded to the World Customs Organization (WCO) in February 2003. The WCO is a UN agency dedicated to dealing with customs administration and related matters. As Bhutan's economy modernizes and its trading activities expand, the WCO will facilitate trans-border trade and improve surveillance. Bhutan will also benefit from various technical assistance, personnel training and establishment of working relations with customs agencies in other member countries.

3.12 The Royal Government acceded to the International Finance Corporation (IFC) in December 2003. The IFC is a member of the World Bank Group that serves as a multilateral source of loan and equity financing for private sector projects in developing countries. Membership in the IFC will benefit our private sector immensely through access to large international financing as well as technical assistance. The ability of the private sector to access such foreign capital will be based solely on the economic viability of the project and not be dependent on any government intervention or guarantees.

\subsection{BIMST-EC (Bangladesh, India, Myanmar, Sri Lanka, Thailand-Economic Cooperation)}

With an objective to expand our economic relations with the SAARC and South East Asian countries, Bhutan joined the BIMST-EC in 2004. During the Sixth BIMST-EC Ministerial Meeting in Phuket, Thailand, in 2004, Bhutan and Nepal were formally admitted as new members. Bhutan also became a signatory to the BIMST-EC Free Trade Area. Membership in this regional grouping will enable 
Bhutan to diversify its export markets and link transport infrastructure while harnessing other potential benefits of expanding economic relation beyond SAARC region.

\subsection{Asian Highway Network}

During the Sixtieth Session of UNESCAP at Shanghai, China in April 2004, Bhutan along with 22 other countries signed the Intergovernmental Agreement on the Asian Highway Network. With 140,000 kms in span, the Asian highway Network will extend to 32 Asian countries, linking the capital cities and other major commercial centers. It is expected to open opportunities, especially for landlocked central Asian countries, to reach the European markets.

\subsection{SAFTA (South Asia Free Trade Area)}

The Framework Agreement on South Asia Free Trade Area (SAFTA), which was signed by Bhutan during the XII SAARC Summit in Islamabad, Pakistan, is expected to open up new market for Bhutanese products as well as help in deeper economic integration with the countries in the region.

\section{Medium Term Expenditure Framework (MTEF)}

4.1 In an effort to strengthen the budget process and the management of public expenditures, the RGoB had conducted its annual plan discussions for 2003-04 and introduced a two-year rolling budget from that fiscal year onwards. As a part of these endeavors, some of the key features of an MTEF have been developed here. Based on estimates of recent economic developments and the outlook described in the above sections, a provisional MTEF, covering the preceding two financial years and next three financial years, is presented in Table 3.

4.2 The MTEF is based on the Ninth Plan financial projections. The total Ninth Plan outlay is $\mathrm{Nu}$. 70,000 million, of which $\mathrm{Nu}$. 31,682 million is for current expenditures, Nu. 34,869 million for capital investments and $\mathrm{Nu}$. 3,449 million is for debt servicing. Current expenditure is to be covered by domestic revenue of $\mathrm{Nu}$. 32,000 million, while external resources amounting to $\mathrm{Nu}$. 28,000 million (earlier estimate was $\mathrm{Nu}$. 35,000 million comprising grant of $\mathrm{Nu}$. 30,000 and loan of $\mathrm{Nu} .5,000)$ is expected to cover capital investments. Out of the total external resources, approximately $\mathrm{Nu}$. 21,000 million is grant assistance and over $\mathrm{Nu}$. 7,000 million is concessionary loans. The RGoB may have to meet the budgetary gap of over Nu. 5,000 million by domestic borrowings.

4.3 Public spending continues to focus on poverty reduction and economic growth, emphasizing infrastructure development and social services. Greater detail on the sectoral priorities as outlined in the Ninth Plan is presented in the section below on Sectoral Strategies. 


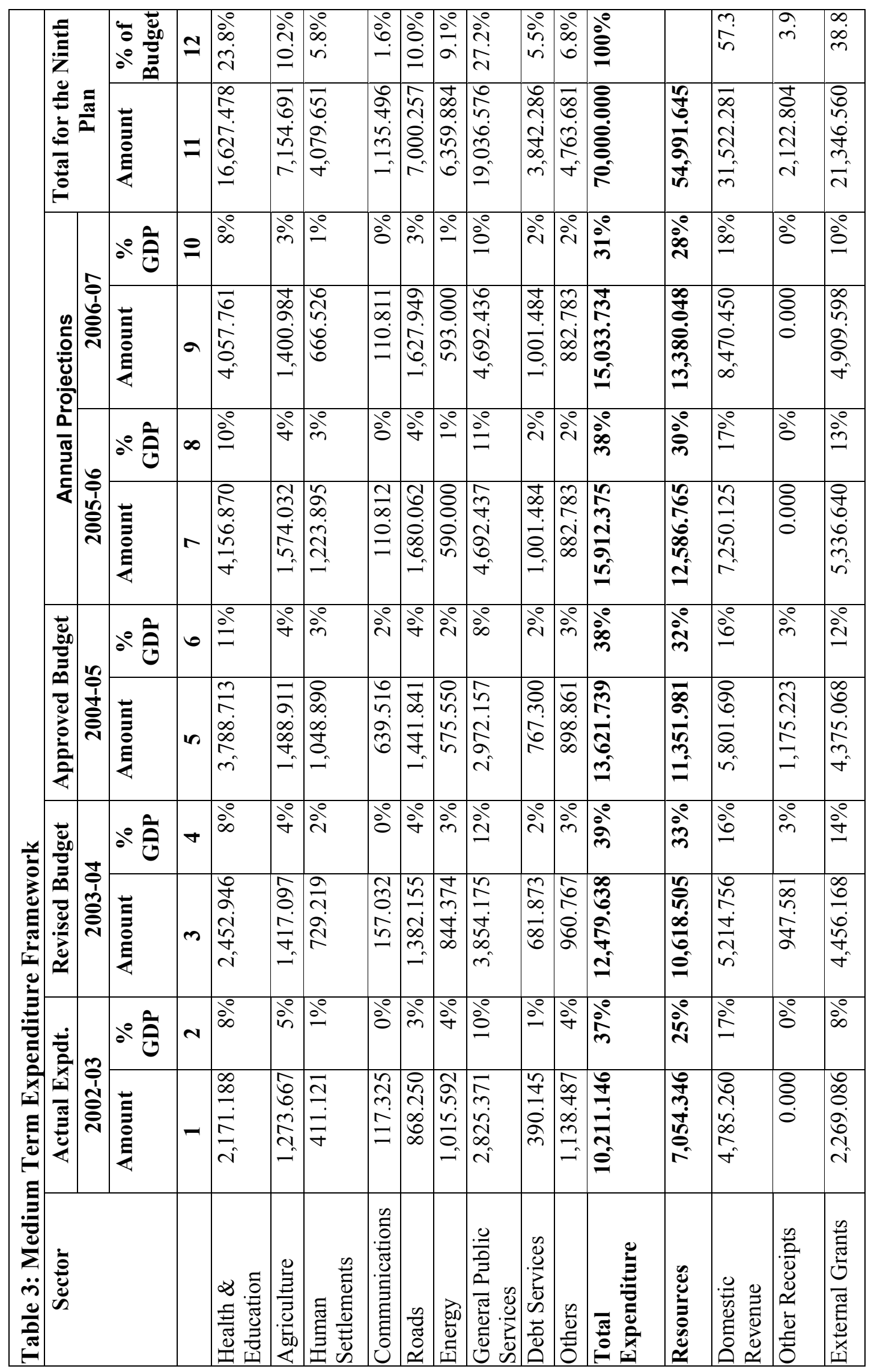



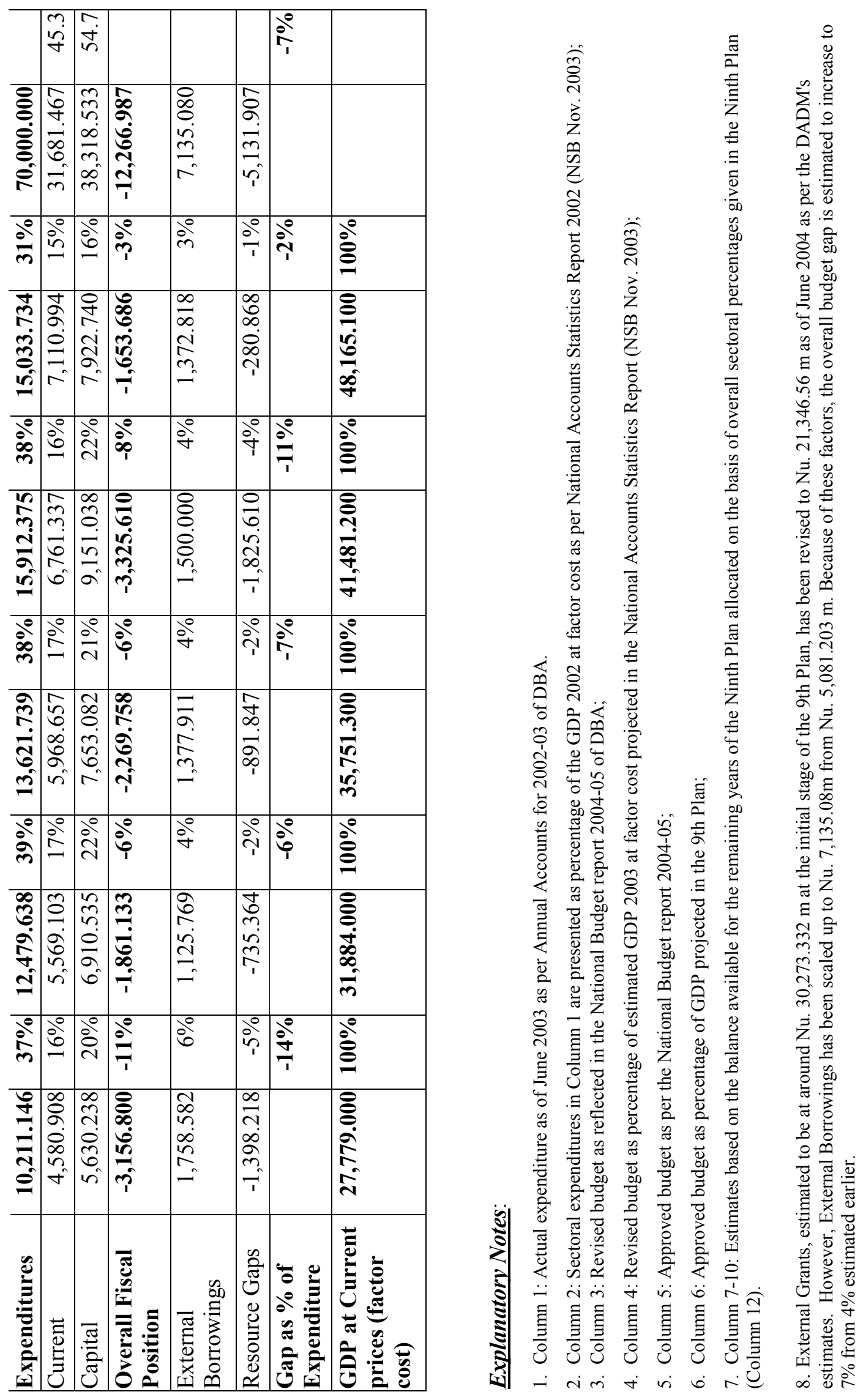


\section{Review of Actual Expenditure for 2002-03}

4.4 Like earlier Plans, the first year of the $9^{\text {th }}$ Plan was a preparatory phase of the Plan. Being the first experimental year for implementation of Gewog-based plans, it faced numerous constraints. Firstly, all 2001 Gups had to be elected as per the universal adult franchise, which was carried out nationwide during the year 2002. Given the absence of any particular agency and/or Election Commission, the task was entrusted to the respective Dzongkhags. This event necessitated the engagement of most of the field officials during the election thus leaving the Dzongkhags with limited time and manpower to implement the plan activities as scheduled. Secondly, the provision of training and orientation to the newly elected Gups took away much of their initial time and this caused delay in the overall supervision of plan activities particularly at the Gewog level. Thirdly, most of the capital activities had to be kept in abeyance because of the non-receipt of external funds as the negotiations were still under progress.

4.5 However, as far as the overall expenditure is concerned, the $9^{\text {th }}$ Plan targets have not been severely affected as the 2002-03 expenditure accounted for nearly $15 \%$ of the total plan outlay against the government's target of $16 \%$. The total expenditure was $\mathrm{Nu} .10,211.146$ million of which $\mathrm{Nu}$. 4580.908 million $(45 \%)$ was current expenditure and $\mathrm{Nu} .5630 .238$ million (55\%) was capital expenditure. In line with the pro-poor policy of the government, most of the expenditure was geared towards infrastructure development, and expenditure for social sectors was $22 \%$ followed by RNR sector with $12 \%$. Although there were numerous enhancement of remuneration especially for Chimi, Mangmi, Gup, Gewog clerks and enhanced travel benefits for support staff in government offices, besides other hosts of recurrent costs, the current expenditures in 2002-03 were lower from that of 2001-02 by about $2 \%$. This was possible due to stringent fiscal management by the Royal Government.

4.6 The overall fiscal deficit is estimated to have widened to 11 percent of GDP in 2002-03 from 6.7 percent in 2001-02 mainly due to resource uncertainties on account of issues related to project readiness and finalization of negotiations with donors.

4.7 On the resource side, domestic revenue and other receipts were on target. Domestic revenue was able to cover the current expenditure once again. The first year of the implementation of the Personal Income Tax resulted in total collection of Nu. 91 millions. With regard to external assistance, grants from donors other than India increased by over 13 percent but grants from the Government of India (GoI) were significantly lower than projected. As a consequence, the resource gap increased substantially to around 14 percent of the actual expenditure. 


\section{Review of Revised Budget for 2003-04}

4.8 The Royal Government was able to narrow down the overall fiscal deficit to about 6 percent of GDP. This improvement in the fiscal position was largely due to sustained economic growth and receipt of projected external grants, especially grants from India. One of the most important developments that had an impact on the national budget was the creation of three new ministries: Ministry of Labour and Human Resources, bifurcations of the Ministry of Health \& Education and the Ministry of Communications. The objective of creating these new institutions was to further strengthen and enhance the performance of the RGoB in its various functions.

4.9 The revised budget for the fiscal year 2003-2004 had exceeded the actual expenditure of the past year by about 22 percent or Nu.2268.492 million. The capital and current expenditures had increased by around 23 percent and 22 percent respectively over the past financial year. The revised budget had increased by around $8 \%$ from the original estimates of $\mathrm{Nu}$. 11,537.737 million.

4.10 On the expenditure side, most of the increase was on account of current expenditures, in particular, the interest subsidy to the DrukAir Corporation, the membership fees for acceding to the International Finance Corporation (IFC), and new appointments in the civil service. As a result, current expenditure coverage by domestic revenues would be around $94 \%$. However, every effort is made to keep the expenditures within the original budget, especially the current expenditures within the domestic resources envelope. Regarding the capital expenditures, there was a relatively small increase, and one of the major factors, besides others, contributing to the increase was the provision for the restoration of roads damaged by monsoon.

4.11 On the resources side, there was a shortfall in program grants of around $\mathrm{Nu} .176$ million. This was mainly because at the time of budget preparation, negotiations with some large donors had not been completed. This shortfall together with increase in expenditures would lead to an additional deficit of around $\mathrm{Nu} .352$ million over what was projected. Further, expected receipts of substantial amounts of grants for various projects did not materialize as the projects took time to be finalized with the development partners. Consequently, any shortfall arising out of it has to be met from domestic borrowings in order to maintain the level of expenditures. However, the revised resource gap is still lower than the past years level.

4.12 A significant feature of the 2003-2004 budget was decentralization and the increasing role played by the peoples' representatives, especially GYTs and DYTs, in the management and use of government funds. There were a number of implications from this change. Firstly, unlike the past, it provided peoples' representatives greater control over resources. Secondly, their accountability to the government, and more importantly to their constituents, on the management 
and use of public funds has been increased. To facilitate decentralization, the Ministry of Finance had initiated the Gewog based budgeting system. Additional finance personnel have been trained and posted to the Dzongkhag to cater to the needs of Gewogs.

4.13 In line with the GYT Chathrim 2002, the Gewogs were allowed to retain rural taxes. It was expected that with time and the experience gained in the management and use of these funds, the process of decentralization would be further strengthened. A common feature of all the Gewog budgets was the request for funds for the construction of Gups' offices. Unlike the past, with expanded roles and responsibilities of the Gup, as well as to ensure continuity and convenience for the people, there was a need for a more permanent office establishment to support this important institution. Thus RGoB would support construction of Gups offices but in a phased manner. Also, there were numerous other Gewog infrastructure needs such as Renewable Natural Resource (RNR) Centres being planned by the government. To ensure maximum benefit and convenience to the people, the Royal Government would coordinate the construction of these facilities to create an Integrated Gewog Development Centre (basically a Gewog Headquarter). Over time, this is expected to become a growth centre that would create economic opportunities including employment for the Gewogs in addition to cost and convenience benefits. It should also create an additional market for village produce and bring in other benefits in much the same manner as the Dzongkhag towns.

\section{Review of Approved Budget for 2004-05}

4.14 While preparing the annual budget for the financial year 2004-05, several factors have been taken into consideration, amongst others the policy of fiscal sustainability including resource availability, backlog activities of the preceding years which could not be implemented due to various reasons and focus on the Gewog-based programmes. Accordingly, the expenditure budget for the year has been drawn up at $\mathrm{Nu}$. 13,621.739 million, out of which $\mathrm{Nu}$. 5,968.657 million (44\%) is for recurrent expenditure and $\mathrm{Nu} .7,158.342$ million (56\%) is for capital expenditure.

4.15 The focus of the financial year 2004-05 continues to be on rural development which includes large outlays on rural electrification, feeder and farm roads, health and education infrastructure in the Dzongkhags. Other capital activities include low-income housing, the construction of the hangar for the new airplanes, construction of roads and population census programmes. These make up the bulk of the capital expenditure budget. The outlay for infrastructure, including buildings and roads, accounted for around $64 \%$ of capital expenditure. About $8 \%$ of the capital expenditure outlay is allocated for human resource development.

4.16 With respect to current expenditure, it is $7 \%$ higher than the revised budget estimates of 2003-04. As in the past year, the wage bill is the single largest item, 
accounting for around 38\%. Interest payments constitute around $6 \%$ of the current expenditure, subsidies to corporations around $4 \%$ and about $8 \%$ for maintenance of infrastructure.

4.17 On the resource side, domestic revenues are expected to finance around $42 \%$ of the total expenditures, grants around $32 \%$ and concessional borrowings about $10 \%$. The balance has to be financed through domestic borrowings. Total revenue is projected to increase by about $11 \%$ over the past year and most of the growth is projected to accrue from Non-tax revenue. Unlike preceding years, the government's fiscal objective of current expenditure coverage by domestic revenues is expected to fall short in the financial year 2004-05. This is mainly because of the increasing current expenditures such as on the maintenance of growing infrastructure and public services, while the growth in revenue is not keeping pace due to the narrow tax base.

4.18 The external assistance, including grants and borrowings, is expected to fund around $80 \%$ of the capital expenditure or around $42 \%$ of the total budget outlay. While the Royal Government would like to finance all the capital expenditures of the $9^{\text {th }}$ Plan through grant financing, the overall grants available are likely to be significantly below the requirement. Further, while concessional borrowings are expected to offset some of the projected shortfall, the balance will have to be made up by increase in domestic borrowing which is expected to finance around $7 \%$ of the budget of the financial year 2004-05, as against about $6 \%$ in the revised budget of 2003-04.

4.19 One of the significant characters of the 2004-05 financial year is the dramatic increase in the budget for activities to be executed by the Gewogs in line with the decentralization policy. A sum of $\mathrm{Nu} .452$ million has been budgeted for the Gewog activities which represent $62 \%$ increase over the revised estimates for the past year. The total budget provision for Dzongkhags and Gewogs is $31 \%$ higher than the previous year's revised budget. While the budget for Dzongkhags and Gewogs account for around $22 \%$ of the total budget outlay, it does not include budget for activities such as rural electrification, rural telecommunication and rural feeder roads which are implemented by central agencies although they are the direct beneficiaries of these programmes.

4.20 In terms of sectoral allocation of budget, as in the past financial years, as well as in line with the priority setting of the $9^{\text {th }}$ plan, social sectors, including health and education, have been allocated around $28 \%$ while the RNR and road sectors have been allocated around $11 \%$ each. 


\section{Outlook for 2005-06 to 2006-07}

4.21 This provisional MTEF is based on the economic outlook discussed above and the overall Ninth Plan priorities. Given the actual expenditure of 2002-03, revised estimate budget of 2003-04 and approved estimated budget for 2004-05, the pace of implementation will need to accelerate sharply in the remaining two years, especially in the second last year of the Ninth Plan if the overall goals are going to be met.

4.22 The overall fiscal deficit is to remain at or below 4-5 percent of GDP. This will depend on a substantial increase in external grants to finance capital investment projects as implementation advances and gains momentum.

4.23 The expenditures are expected to increase in nominal terms but remain below 40 percent of the GDP, with capital expenditure accounting for approximately 55 percent of the total budget. The annual projections are based on what remains from the Ninth Plan overall outlay after taking into account the expenditures of 2002-03, revised budget of 2003-04 and the approved budget for 2004-05 (covering the first three years of the Ninth Plan). In addition, the path of expenditure to GDP ratio was also considered in making the projections.

4.24 On the resource side, the estimated domestic revenue is expected to continue covering the current expenditure with domestic revenue remaining at around 1718 percent of the GDP. The external grants are expected to increase in the coming years such that the overall plan targets will be met. The projections are again based on what remains from the Ninth Plan overall resources anticipated after taking into account the revenues of the past three financial years. The projected resource gap of about 4-5 percent is planned to be covered through concessionary loans of about 3-4 percent of GDP and the balance through domestic borrowings of about 2-3 percent of GDP.

\section{Special Considerations}

4.25 One of the significant changes during the Ninth Plan has been the introduction of Gewog $^{2}$ (Block) Plans, whereby individual developmental plan and costing were performed for each Gewog. Accordingly, the budgetary allocations have been divided into central, Dzongkhag (District) and Gewog budgets. From the total budgetary outlay of $\mathrm{Nu}$. 70,000 million, about 75 percent is allocated to the center, $21 \%$ to the Dzongkhag and $4 \%$ to the Gewogs. While the percentage of budget allocated to the Dzongkhag and Gewogs appears small in comparison to the allocations made to the Centre, the programs proposed for implementation by the Centre are all for the benefit of the Dzongkhag and Gewogs, and therefore the actual expenditures would be much more than indicated.

\footnotetext{
${ }^{2}$ There are 201 Gewogs in 20 Dzongkhags
} 
4.26 The Central programs include those that require large investments, a high level of technical expertise, and inter-Dzongkhag coordination Therefore, programs such as rural electrification, rural access roads, rural telecommunications, purchase of farm machineries and equipment, and the human resource development of the Dzongkhag and Gewogs are budgeted in the center.

4.27 The Dzongkhags will be responsible for implementation of programs that require inter-Gewog coordination, institutional strengthening and capacity development of their sectoral human resources. While Gewog programs will be implemented by the Gewogs themselves, the Dzongkhag will be responsible for the coordination, supervision, quality control and providing technical backstopping to the Gewogs. The largest portion of the Dzongkhag budget is allocated to the Education sector as the responsibility of establishing and maintaining the educational infrastructure at the lower secondary, middle secondary and higher secondary levels have been devolved to the Dzongkhag from the center. The construction of district hospitals, Basic Health Units and development of satellite townships in the Dzongkhag are some of the other major programs included in the Dzongkhag budget.

4.28 Gewog programs consist mainly of social and rural infrastructure development such as construction of farm roads, out reach clinics, primary and community schools, irrigation facilities, suspension bridges and mule tracks and rural water supply schemes. These programs were prioritized by the Gewogs based on potential, needs and their ability to participate in terms of labour contribution, land acquisition, etc. The agriculture sector receives the highest budgetary allocation, as the Gewogs would implement most of the activities in this sector with technical support from the Dzongkhag.

\section{Sectoral Strategies}

5.1 The MTEF presented in the previous section and the Ninth Plan places strong emphasis on poverty reduction and this is reflected in the sectoral strategies described below. As shown on Table 4, the Ninth Plan focuses on enhanced access to health and education facilities, and infrastructure development such as roads, electricity and rural telecommunications. Thus, 24 percent of the total budget is allocated to the social sectors (health and education) followed by roads, agriculture and electricity, each receiving an allocation of 10 percent of the total. These strategies are consistent with the MDGs. 
Table 4: Sectoral Allocations as laid out in the Ninth Plan

\begin{tabular}{|c|c|c|c|c|c|c|c|c|}
\hline Sectors & Centre & $\%$ & Dzongkhag & $\%$ & Geog & $\%$ & Total & $\%$ \\
\hline \begin{tabular}{|l|} 
Health \\
Education
\end{tabular} & $7,102.800$ & $13.4 \%$ & $8,946.560$ & $60.1 \%$ & 578.123 & $25.8 \%$ & $16,627.483$ & $23.8 \%$ \\
\hline Agriculture & $4,548.361$ & $8.6 \%$ & $1,561.415$ & $10.5 \%$ & $1,044.915$ & $46.6 \%$ & 7,154.691 & $10.2 \%$ \\
\hline $\begin{array}{l}\text { Human } \\
\text { Settlement }\end{array}$ & $2,587.379$ & $4.9 \%$ & $1,492.272$ & $10.0 \%$ & & $0.0 \%$ & $4,079.651$ & $5.8 \%$ \\
\hline Communications & $1,135.495$ & $2.1 \%$ & & $0.0 \%$ & & $0.0 \%$ & $1,135.495$ & $1.6 \%$ \\
\hline Roads & $6,660.259$ & $12.6 \%$ & 135.650 & $0.9 \%$ & 204.347 & $9.1 \%$ & $7,000.256$ & $10.0 \%$ \\
\hline Energy & $6,217.949$ & $11.8 \%$ & 141.935 & $1.0 \%$ & & $0.0 \%$ & $6,359.884$ & $9.1 \%$ \\
\hline $\begin{array}{ll}\text { General } & \text { Public } \\
\text { Services } & \\
\end{array}$ & $16,021.010$ & $30.3 \%$ & $2,602.183$ & $17.5 \%$ & 413.385 & $18.4 \%$ & $19,036.578$ & $27.2 \%$ \\
\hline Debt Service & $3,842.286$ & $7.3 \%$ & & $0.0 \%$ & & $0.0 \%$ & $3,842.286$ & $5.5 \%$ \\
\hline Others & $4,763.680$ & $9.0 \%$ & & $0.0 \%$ & & $0.0 \%$ & $4,763.680$ & $6.8 \%$ \\
\hline Total & $52,879.219$ & $100.0 \%$ & $14,880.015$ & $100.0 \%$ & 240.770 & $100.0 \%$ & $70,000.000$ & $100.0 \%$ \\
\hline $\begin{array}{lll}\% & \text { of } & \text { Total } \\
\text { Outlay } & \\
\end{array}$ & & $75.5 \%$ & & $21.3 \%$ & & $3.2 \%$ & & $100.0 \%$ \\
\hline
\end{tabular}

\section{Education Sector:}

5.2 Current situation: The high priority given to the education sector has resulted in an increase in the gross primary enrolment ratio from 55 percent in 1991 to 81 percent in 2003, an annual increase of about 6-7 percent. The girl's enrolment ratio has also risen significantly, from 39 percent in 1990 to 47 percent in 2003. There has also been a substantial rise in the share of school children completing seven years of primary school (grades 1 through 7), doubling in the 1990s to reach 69 percent in 2001. Adult literacy increased from 48 percent in 1994 to 54 percent in 2000. This progress suggests that Bhutan is on track to achieve the MDGs related to education.

5.3 While significant progress has been made, the education sector is still confronted with several challenges. The difficult terrain and widely scattered population makes provision of educational services very costly and does not allow economies of scale. The education system as a whole suffers from a critical shortage of educational facilities and an inadequate number of qualified and competent teachers. The retention rate, while it has improved over the years, still remains high. Of the 100 children enrolling in primary schools, only 69 complete seven years of primary education, 54 complete Class VIII and 39 reach class X. The repetition rate remains high at an annual average of 14 percent. 
5.4 Objectives: The main goals set out for the Ninth Plan include:

- Providing support mechanisms for early childhood care and development for children between 0-6 years on a pilot basis;

- Enhancing enrolment of children between 6-12 years of age in primary schools to $90-95$ percent by 2007 ;

- Enhancing the quality of education comparable to international standards;

- Improving and expanding youth guidance and career counseling and value education for wholesome development of the youth;

- Increasing the basic level from class VIII to X;

- Increasing promotion proportion from class X to XI from 38 percent to 56 percent by 2007;

- Developing a higher education system under the umbrella of a National University;

- Enhancing the literacy rate from 54 percent to 80 percent and establish a system of continuing and life long education opportunities;

- Establishing a program of inclusive education for children who are physically and mentally challenged;

- Strengthening and improving the education management system with particular emphasis on the school level management; and

- Developing a more sustainable education system through the introduction of private participation and cost sharing measures.

5.5 Strategies: The main thrust of the Education sector strategy in the Ninth Plan is to increase access and reach the un-reached, further develop the curriculum, improve the teacher pupil ratio, and expand educational facilities. The major programs proposed to improve the quality of education include: a) constructing 120 community schools, 26 lower secondary and 23 middle and higher secondary schools, b) expanding the facilities at Sherubtse College to increase enrollment from 600 to 1000 students, c) increasing facilities at the two in-country teachers training institutes to increase the intake of trainee teachers from 900 to 1,470, d) providing special education for the disabled, e) continuing adult literacy programs, and e) establishing the national university of Bhutan.

5.6 Financing: The continued high priority given to the education sector has been translated into a spending allocation of 15 percent of the total budget (Table 5). 
Table 5: Projected Annual Expenditure \& Allocations

\begin{tabular}{|c|c|c|c|c|c|c|c|c|c|c|c|c|}
\hline \multirow[t]{3}{*}{ Education } & \multirow{2}{*}{\multicolumn{2}{|c|}{\begin{tabular}{|c|} 
Actual Expt. \\
$2002-03$ \\
\end{tabular}}} & \multirow{2}{*}{\multicolumn{2}{|c|}{\begin{tabular}{|c|}
$\begin{array}{c}\text { Revised } \\
\text { Budget }\end{array}$ \\
$2003-04$ \\
\end{tabular}}} & \multirow{2}{*}{\multicolumn{2}{|c|}{$\begin{array}{c}\begin{array}{c}\text { Approved } \\
\text { Budget }\end{array} \\
2004-05 \\
\end{array}$}} & \multicolumn{4}{|c|}{ Annual Projections } & \multirow{2}{*}{\multicolumn{2}{|c|}{$\begin{array}{l}\text { Total for the } \\
\text { Ninth Plan }\end{array}$}} \\
\hline & & & & & & & \multicolumn{2}{|c|}{ 2005-06 } & \multicolumn{2}{|c|}{ 2006-07 } & & \\
\hline & Amt. & \begin{tabular}{|c|}
$\%$ \\
Sector \\
Budget
\end{tabular} & Amt. & \begin{tabular}{|c|}
$\%$ \\
Sector \\
Budget
\end{tabular} & Amt. & $\begin{array}{c}\text { \% } \\
\text { Sector } \\
\text { Budget }\end{array}$ & Amt. & \begin{tabular}{|c|}
$\%$ \\
Sector \\
Budget
\end{tabular} & Amt. & \begin{tabular}{|c|}
$\%$ \\
Sector \\
Budget
\end{tabular} & Amt. & \begin{tabular}{|c|}
$\%$ \\
Sector \\
Budget
\end{tabular} \\
\hline Curr & 988.0 & $75 \%$ & 1046.7 & $71 \%$ & 1221.1 & $55 \%$ & 1089.4 & $41 \%$ & 1006.2 & $40 \%$ & 5351.4 & 52 \\
\hline Capital & 334.5 & $25 \%$ & 433.5 & $29 \%$ & 1017.4 & $45 \%$ & 1540.0 & $59 \%$ & 1532.6 & $60 \%$ & 4858.0 & $48 \%$ \\
\hline Total & 1322.5 & $100 \%$ & 1480.2 & $100 \%$ & 2238.5 & $100 \%$ & 2629.4 & $100 \%$ & 2538.8 & $100 \%$ & 10209.4 & $100 \%$ \\
\hline Centre & 526.4 & $40 \%$ & 505.5 & $34 \%$ & 932.9 & $42 \%$ & 320.1 & $12 \%$ & 311.7 & $12 \%$ & 2596.9 & $25 \%$ \\
\hline Dzongkhag & 792.1 & $60 \%$ & 931.8 & $63 \%$ & 1250.5 & $56 \%$ & 2166.1 & $82 \%$ & 2123.7 & $84 \%$ & 7264.2 & $71 \%$ \\
\hline Geog & 4.0 & $0 \%$ & 42.9 & $3 \%$ & 55.1 & $2 \%$ & 143.2 & $5 \%$ & 103.4 & $4 \%$ & 348.3 & 0 \\
\hline Total & 1322.5 & $100 \%$ & 1480.2 & $100 \%$ & 2238.5 & $100 \%$ & 2629.4 & $100 \%$ & 2538.8 & $100 \%$ & 10209.4 & $100 \%$ \\
\hline
\end{tabular}

\section{Health Sector:}

5.7 Current situation: The results of the National Health Survey conducted in 2000 (Table 6) shows that substantial progress has been made since 1994. About 78.2 percent of Bhutanese villages have access to health facilities within two hours walking distance, and about 89 percent have such services within three hours walking distance. On current trends, Bhutan is likely to reach the MDGs related to health.

5.8 The rugged terrain and sparse population continue to pose major obstacles to the delivery of health services. Efficient and effective delivery of these services to the remotest areas will depend in part on using modern technologies such as telemedicine and alternative methods.

Table 6: Heath Indicators

\begin{tabular}{|l|l|l|}
\hline & $\mathbf{1 9 9 4}$ & $\mathbf{2 0 0 0}$ \\
\hline Infant Mortality Rate per 1000 live births & 70.7 & 60.5 \\
\hline Under five Mortality Rate per 1000 live births & 96.9 & 84.0 \\
\hline Maternal Mortality Rate per 1000 live births & 3.8 & 2.55 \\
\hline Crude Birth Rate per 1000 population & 39.9 & 34.09 \\
\hline Crude Death Rate per 1000 population & 9.0 & 8.64 \\
\hline Contraceptive Prevalence Rate \% & 18.8 & 30.7 \\
\hline Access to Safe Drinking Water \% & $\mathrm{NA}$ & 77.8 \\
\hline Sanitation Coverage \% & $\mathrm{NA}$ & 88.0 \\
\hline Average Life Expectancy at Birth & 66 & $\mathrm{NA}$ \\
\hline Population Growth Rate \% & 3.1 & 2.5 \\
\hline
\end{tabular}

National Health Survey 1994 \& 2000 
5.9 Objectives: The RGoB seeks to further improve the health status of Bhutan by: a) improving the quality of health services, b) expanding access to reach the unreached, c) enhancing the sustainability of health services, d) strengthening the health management information system and research, e) intensifying reproductive health services and family planning, f) addressing and controlling existing and emerging health problems, and g) strengthening the traditional medicine system and integrating it with general health services. The RGoB expects several health related targets to be met by the end of the Ninth Plan, and seeks to facilitate 100 percent access to clean water and safe sanitation, slow the population growth rate to 2.3 percent, halve infant mortality per 1000 live births to 30 , reduce the under-5 mortality rate per 1000 live births from 84 to 50, and lower the maternal mortality rate from 2.6 to 1.5 .

5.10 Strategies: The major goals of the Health Sector include a) improving the doctor patient ratio through human resource development, b) monitoring and preventing STD/HIV/AIDS through information, education and communication programs, and c) enhancing the financial sustainability of health services, particularly for ensuring the availability of essential drugs and vaccines.

5.11 Financing: The health sector is budgeted to receive Nu. 6,418 million or about 10 $\%$ of the total Ninth Plan outlay (Table 7). Although spending during the first year of the Ninth Plan has been slower than anticipated, activity will increase in the coming years.

Table 7: Projected Annual Expenditure \& Allocations

\begin{tabular}{|c|c|c|c|c|c|c|c|c|c|c|c|c|}
\hline \multirow[t]{3}{*}{ Health } & \multirow{2}{*}{\multicolumn{2}{|c|}{$\begin{array}{c}\begin{array}{c}\text { Actual } \\
\text { Expt. }\end{array} \\
\text { 2002-03 }\end{array}$}} & \multirow{2}{*}{\multicolumn{2}{|c|}{$\begin{array}{c}\text { Revised } \\
\text { Budget }\end{array}$}} & \multirow{2}{*}{\multicolumn{2}{|c|}{$\begin{array}{c}\begin{array}{c}\text { Approved } \\
\text { Budget }\end{array} \\
2004-05 \\
\end{array}$}} & \multicolumn{4}{|c|}{ Annual Projections } & \multicolumn{2}{|c|}{$\begin{array}{l}\text { Total for the } \\
\text { Ninth Plan }\end{array}$} \\
\hline & & & & & & & \multicolumn{2}{|c|}{ 2005-06 } & \multicolumn{2}{|c|}{ 2006-07 } & & \\
\hline & Amt. & $\begin{array}{c}\% \\
\text { Sector } \\
\text { Budget }\end{array}$ & Amt. & $\begin{array}{c}\% \\
\text { Sector } \\
\text { Budget }\end{array}$ & Amt. & \begin{tabular}{|c|}
$\%$ \\
Sector \\
Budget
\end{tabular} & Amt. & \begin{tabular}{|c|}
$\%$ \\
Sector \\
Budget
\end{tabular} & Amt. & \begin{tabular}{|c|}
$\%$ \\
Sector \\
Budget
\end{tabular} & Amt. & \begin{tabular}{|c|}
$\%$ \\
Sector \\
Budget
\end{tabular} \\
\hline Curre & 561.7 & $66 \%$ & 650.1 & $67 \%$ & 704.5 & $45 \%$ & 1007.5 & $66 \%$ & 101 & $66 \%$ & 393 & \\
\hline Capital & 287.0 & $34 \%$ & 322.7 & $33 \%$ & 845.7 & $55 \%$ & 520.0 & $34 \%$ & 508.9 & $34 \%$ & 2484.3 & $39^{\circ}$ \\
\hline Total & 848.7 & $100 \%$ & 972.7 & $100 \%$ & 1550.2 & $100 \%$ & 1527.5 & $100 \%$ & 1518.9 & $100 \%$ & 6418.1 & $100 \%$ \\
\hline entre & 642.8 & $76 \%$ & 724.1 & $74 \%$ & 1239.3 & $80 \%$ & 950.8 & $62 \%$ & 948.8 & $62 \%$ & 4505.8 & $70^{\circ}$ \\
\hline Dzongkhag & 205.6 & $24 \%$ & 237.6 & $24 \%$ & 297.3 & $19 \%$ & 480.0 & $31 \%$ & 461.9 & $30 \%$ & 1682.4 & $26 \%$ \\
\hline Jeog & 0.3 & $0 \%$ & 11.0 & $1 \%$ & 13.6 & $1 \%$ & 96.7 & $6 \%$ & 108.2 & $7 \%$ & 229.8 & $4 \%$ \\
\hline otal & 848.7 & $100 \%$ & 972.7 & $100 \%$ & 1550.2 & $100 \%$ & 1527.5 & $100 \%$ & 1518.9 & $100 \%$ & 6418.1 & $100 \%$ \\
\hline
\end{tabular}




\section{Agricultural Sector (Renewable Natural Resources):}

5.12 Current Situation: The most recent Poverty Assessment Report conducted in 2000 shows that there is a grain deficit in 63 out of 201 Gewogs, such that a substantial portion of poor household income is spent on buying food grains. This is mainly due to poor productivity and shortage of cultivable land. Average land holding per rural household consisting of family of six members was 3.4 acres, and fragmentation is a major concern. About 79 percent of the population lives in rural areas and 75 percent of the workforce is engaged in RNR.

5.13 The major challenges for the sector in the Ninth Plan will be to increase productivity and ensuring equitable distribution of land. The balancing of existing strong environmental conservation policies with the emerging socio-economic needs would be an important challenge to be addressed. Shortages of farm labour due to increasing rural-urban migration is becoming a major problem

5.14 Objectives: The objectives of the agriculture sector set out for the Ninth Plan are:

- Enhancing rural income;

- Achieving national food security;

- Conserving and managing natural resources; and

- Generating employment opportunities.

5.15 Strategies: The major strategies include a) creation enabling policy and legal framework; b) farm mechanization and use of appropriate technology; c) increasing access through creation of new infrastructure; d) diversifications and encouraging "high value and low volume" products; and e) research and development.

5.16 Financing: Given that agriculture sector plays a crucial role in rural development, the Ninth Plan allocates close to 10 percent of the total budget to fund improvements in the sector. 
Table 8: Projected Annual Expenditure \& Allocations

\begin{tabular}{|c|c|c|c|c|c|c|c|c|c|c|c|c|}
\hline \multirow[t]{3}{*}{ RNR } & \multirow{2}{*}{\multicolumn{2}{|c|}{\begin{tabular}{|c|} 
Actual Expt. \\
$2002-03$ \\
\end{tabular}}} & \multirow{2}{*}{\multicolumn{2}{|c|}{$\begin{array}{l}\begin{array}{l}\text { Revised } \\
\text { Budget }\end{array} \\
2003-04 \\
\end{array}$}} & \multirow{2}{*}{\multicolumn{2}{|c|}{\begin{tabular}{|c|}
$\begin{array}{c}\text { Approved } \\
\text { Budget }\end{array}$ \\
$2004-05$ \\
\end{tabular}}} & \multicolumn{4}{|c|}{ Annual Projections } & \multirow{2}{*}{\multicolumn{2}{|c|}{$\begin{array}{l}\text { Total for the } \\
\text { Ninth Plan }\end{array}$}} \\
\hline & & & & & & & \multicolumn{2}{|c|}{ 2005-06 } & \multicolumn{2}{|c|}{ 2006-07 } & & \\
\hline & Amt. & \begin{tabular}{|c|}
$\%$ \\
Sector \\
Budget
\end{tabular} & Amt. & \begin{tabular}{|c|}
$\%$ \\
Sector \\
Budget
\end{tabular} & Amt. & $\begin{array}{c}\% \\
\text { Sector } \\
\text { Budget }\end{array}$ & Amt. & \begin{tabular}{|c|}
$\%$ \\
Sector \\
Budget
\end{tabular} & Amt. & \begin{tabular}{|c|}
$\%$ \\
Sector \\
Budget
\end{tabular} & Amt. & \begin{tabular}{|c|}
$\%$ \\
Sector \\
Budget
\end{tabular} \\
\hline Current & 574.8 & $45 \%$ & 711.6 & $50 \%$ & 741.2 & $50 \%$ & 740.0 & $47 \%$ & \begin{tabular}{|l|}
741.3 \\
\end{tabular} & $53 \%$ & 3508.9 & $49^{\circ}$ \\
\hline Capital & 698.9 & $55 \%$ & 705.5 & $50 \%$ & 747.7 & $50 \%$ & 834.0 & $53 \%$ & 659.6 & $47 \%$ & 3645.8 & $51 \%$ \\
\hline Total & 1273.7 & $100 \%$ & 1417.1 & $100 \%$ & 1488.9 & $100 \%$ & 1574.0 & $100 \%$ & 1400.9 & $100 \%$ & 7154.7 & $100 \%$ \\
\hline Centre & 1113.7 & $87 \%$ & 1125.2 & $79 \%$ & 1081.7 & $73 \%$ & 1007.0 & $64 \%$ & 844.9 & $60 \%$ & 4548.4 & 64 \\
\hline Dzongkhag & 155.3 & $12 \%$ & 203.3 & $14 \%$ & 245.5 & $16 \%$ & 338.0 & $21 \%$ & 335.0 & $24 \%$ & 1561.4 & $22 \%$ \\
\hline Geog & 4.6 & $0 \%$ & 88.6 & $6 \%$ & 161.7 & $11 \%$ & 229.0 & $15 \%$ & 221.0 & $16 \%$ & 1044.9 & $15 \%$ \\
\hline Total & 1273.7 & $100 \%$ & 1417.1 & $100 \%$ & 1488.9 & $100 \%$ & 1574.0 & $100 \%$ & 1400.9 & $100 \%$ & 7154.7 & $100 \%$ \\
\hline
\end{tabular}

\section{Road Sector:}

5.17 Current Situation: For a landlocked country with no navigable rivers, an efficient and reliable road network plays an important role in socio-economic development of a country. The various poverty surveys carried out in the past reveal that those communities further from the road network are worse off than those near the roads. In view of its importance, the Royal Government has accorded a high priority to infrastructure expansion and building, including roads, during the 9FYP. At present, Bhutan is internally connected with a road network of 4020 kilometers ${ }^{3}$, including 1,558 kilometers of national highway.

5.18 The fragile terrain, scattered population and strong environmental policy make development and maintenance of road network a major challenge in Bhutan.

5.19 Objectives: The main objectives of the road sector in the Ninth Plan are:

- Improving accessibility to social and economic activities by building more roads; and

- Enhancing the existing network with a view to reduce travel time, road user costs and transportation cost for goods and services.

5.20 Strategy: The major strategies include a) the promotion of private sector participation, b) the automation of road works, c) the adoption of environmentally friendly road construction techniques, and d) the construction of 77 kilometers of national highway, 123 kilometers of feeder roads connecting farms roads to the

\footnotetext{
${ }^{3}$ Comparative Socio-economic Indicators for Bhutan, March 2004, NSB
} 
main road networks, and the replacement and the construction of about eight bridges.

5.21 Financing: With an allocation of 10 percent of the total outlay, the road sector will play an important role in improving the socio-economic conditions particularly of the rural farmers.

Table 9: Projected Annual Expenditure \& Allocations

\begin{tabular}{|c|c|c|c|c|c|c|c|c|c|c|c|c|}
\hline \multirow[t]{3}{*}{ Roads } & \multirow{2}{*}{\multicolumn{2}{|c|}{$\begin{array}{c}\begin{array}{c}\text { Actual } \\
\text { Expt. }\end{array} \\
2002-03\end{array}$}} & \multirow{2}{*}{\multicolumn{2}{|c|}{$\begin{array}{c}\text { Revised } \\
\text { Budget }\end{array}$}} & \multirow{2}{*}{\multicolumn{2}{|c|}{$\begin{array}{c}\begin{array}{c}\text { Approved } \\
\text { Budget }\end{array} \\
2004-05 \\
\end{array}$}} & \multicolumn{4}{|c|}{ Annual Projections } & \multirow{2}{*}{\multicolumn{2}{|c|}{$\begin{array}{l}\text { Total for the } \\
\text { Ninth Plan }\end{array}$}} \\
\hline & & & & & & & \multicolumn{2}{|c|}{ 2005-06 } & \multicolumn{2}{|c|}{ 2006-07 } & & \\
\hline & Amt. & $\begin{array}{c}\% \\
\text { Sector } \\
\text { Budget }\end{array}$ & Amt. & $\begin{array}{c}\% \\
\text { Sector } \\
\text { Budget }\end{array}$ & Amt. & \begin{tabular}{|c|}
$\%$ \\
Sector \\
Budget
\end{tabular} & Amt. & $\begin{array}{c}\% \\
\text { Sector } \\
\text { Budget }\end{array}$ & Amt. & \begin{tabular}{|c|}
$\%$ \\
Sector \\
Budget
\end{tabular} & nt. & \begin{tabular}{|c|}
$\%$ \\
Sector \\
Budget
\end{tabular} \\
\hline Curr & 194.4 & $22 \%$ & 206.7 & $15 \%$ & 192.9 & $13 \%$ & 335.4 & $20 \%$ & 33 & 2 & & \\
\hline Capital & 673.8 & $78 \%$ & 1175.4 & $85 \%$ & 1248.9 & $87 \%$ & 1344.7 & $80 \%$ & 128 & $79 \%$ & 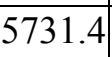 & $82^{\circ}$ \\
\hline Total & 868.3 & $100 \%$ & 1382.2 & $100 \%$ & 1441.8 & $100 \%$ & 1680.1 & $100 \%$ & 1627.9 & $100 \%$ & .3 & $100 \%$ \\
\hline Centre & 836.8 & $96 \%$ & 1337.6 & $97 \%$ & 1412.1 & $98 \%$ & 1540.0 & $92 \%$ & 1533.8 & $94 \%$ & 6660.3 & $95^{\circ}$ \\
\hline zongkhag & 31.4 & $4 \%$ & 31.5 & $2 \%$ & 5.1 & $0 \%$ & 34.8 & $2 \%$ & 32.9 & $2 \%$ & 135.7 & 20 \\
\hline $\operatorname{leog}$ & 0.1 & $0 \%$ & 13.1 & $1 \%$ & 24.6 & $2 \%$ & 105.3 & $6 \%$ & 61.2 & $4 \%$ & 204.3 & $3 \%$ \\
\hline Total & 868.3 & $100 \%$ & 1382.2 & $100 \%$ & 1441.8 & $100 \%$ & 1680.1 & $100 \%$ & 1627.9 & $100 \%$ & 7000.3 & $100 \%$ \\
\hline
\end{tabular}

\section{Energy Sector:}

5.22 Current situation: By the end of the Eighth Plan (2002), the country had harnessed a total of $444 \mathrm{MW}$, equivalent to about 1.4 percent of the total estimated potential of over 30,000 MW. Annual domestic consumption has grown at an average rate of 9.53 percent in the last five years from about $70 \mathrm{MW}$ in 1995 to about $90 \mathrm{MW}$ in 2000. Electricity exports to India increased from 1,354 million units in 1997 to 1,495 millions unit in 2000. Its contribution to the national exchequer was 45 percent of the total revenue generated. The construction of $1020 \mathrm{MW}$ Tala Hydroelectric project and 38.6 MW Basochhu Hydroelectric Project (Lower Stage) is under implementation and expected to be commissioned during the Ninth Plan.

5.23 The main challenge is to continue to harness hydroelectric potential. While Bhutan has an abundant supply of relatively cheap hydroelectric power, there is still about 65 percent of the population without electricity. Bringing electricity to these communities is difficult given the country's topography and low economies of scale for extension of the grid to supply scattered settlements. 
5.24 Objectives: The goals of the hydropower sector set out for the Ninth Plan are:

- Strengthening the economic self-reliance of the nation by realizing the electricity generation capacity;

- Providing adequate, safe and reliable electricity through sustainable and environmentally friendly development of hydroelectric potential; and

- 100 percent rural electrification by 2020 .

5.25 Strategies: The energy sector strategies include a) conducting feasibility studies for micro-hydroelectricity sites where extension of grid supply is not possible, b) expanding rural electrification programs to improve the quality of life and well being of the people living in rural areas, c) studying the feasibility of harnessing 2,000 MW of hydroelectric power, and d) implementing two new hydroelectric power projects namely the 360 MW Mangdechhu Hydroelectric Power Plant and the 870 MW Punatsangchhu Hydroelectric Power Plan during the Ninth Plan. The major activities proposed are a) rural electrification targeting 15,000 households, three-fold increase over the Eighth Plan target of 5,000 household; b) construction of transmission grid from Tingtibi to Trongsa/Bumthang and Wangdue to Tsirang/Dagana and to Gelephu; c) preparation of energy and water resource master plan including feasibility studies of new hydroelectricity projects; and d) institutional strengthening and capacity building of energy sector.

5.26 Financing: The allocation of the energy sector does not include provision for mega hydroelectric projects such as the 360 MW Mangdechhu Hydroelectric Power Plant and the 870 MW Punatsangchhu Hydroelectric Power.

Table 10: Projected Annual Expenditure \& Allocations

\begin{tabular}{|c|c|c|c|c|c|c|c|c|c|c|c|c|}
\hline \multirow[t]{3}{*}{ Energy } & \multirow{2}{*}{\multicolumn{2}{|c|}{\begin{tabular}{|c|} 
Actual Expt. \\
$2002-03$ \\
\end{tabular}}} & \multirow{2}{*}{\multicolumn{2}{|c|}{$\begin{array}{c}\begin{array}{c}\text { Revised } \\
\text { Budget }\end{array} \\
2003-04\end{array}$}} & \multirow{2}{*}{\multicolumn{2}{|c|}{\begin{tabular}{|c|c}
$\begin{array}{c}\text { Approved } \\
\text { Budget }\end{array}$ \\
$2004-05$ \\
\end{tabular}}} & \multicolumn{4}{|c|}{ Annual Projections } & \multicolumn{2}{|c|}{$\begin{array}{l}\text { Total for the } \\
\text { Ninth Plan }\end{array}$} \\
\hline & & & & & & & \multicolumn{2}{|c|}{$2005-06$} & \multicolumn{2}{|c|}{ 2006-07 } & & \\
\hline & Amt. & \begin{tabular}{|c|}
$\%$ \\
Sector \\
Budget
\end{tabular} & Amt. & \begin{tabular}{|c|}
$\%$ \\
Sector \\
Budget
\end{tabular} & Amt. & $\begin{array}{c}\% \\
\text { Sector } \\
\text { Budget }\end{array}$ & Amt. & $\begin{array}{c}\% \\
\text { Sector } \\
\text { Budget }\end{array}$ & Amt. & $\begin{array}{c}\% \\
\text { Sector } \\
\text { Budget }\end{array}$ & Amt. & \begin{tabular}{|c|}
$\%$ \\
Sector \\
Budget
\end{tabular} \\
\hline Current & 23.2 & $2 \%$ & 27.8 & $3 \%$ & \begin{tabular}{|c|}
32.9 \\
\end{tabular} & $6 \%$ & 40.0 & $7 \%$ & 43.0 & $7 \%$ & $|1857.4|$ & $29 \%$ \\
\hline Capital & 992.4 & $98 \%$ & 816.6 & $97 \%$ & 542.6 & $94 \%$ & 550.0 & $93 \%$ & 550.0 & $93 \%$ & \begin{tabular}{|c|}
4502.5 \\
\end{tabular} & $71 \%$ \\
\hline Total & 1015.6 & $100 \%$ & 844.4 & $100 \%$ & 575.6 & \begin{tabular}{|l|l|}
6 & $100 \%$ \\
\end{tabular} & 590.0 & $100 \%$ & 593.0 & $100 \%$ & 6359.9 & $100 \%$ \\
\hline & & & & & & & & & & & & \\
\hline Centre & 1015.6 & $100 \%$ & 844.4 & $100 \%$ & \begin{tabular}{|l|}
575.6 \\
\end{tabular} & $100 \%$ & 590.0 & $100 \%$ & 6593.0 & $100 \%$ & 6217.9 & $98 \%$ \\
\hline Dzongkhas & 0.0 & $0 \%$ & 0.0 & $0 \%$ & 0.0 & $0 \%$ & 0.0 & $0 \%$ & \begin{tabular}{|c|c}
0 & 0.0 \\
0
\end{tabular} & $0 \%$ & \begin{tabular}{|c|}
141.9 \\
\end{tabular} & $2 \%$ \\
\hline Total & 1015.6 & $100 \%$ & 844.4 & $100 \%$ & 575.6 & \begin{tabular}{|l|l|}
5 & $100 \%$ \\
\end{tabular} & 590.0 & $100 \%$ & 593.0 & $100 \%$ & 6359.9 & $100 \%$ \\
\hline
\end{tabular}

Note: As the activities are being implemented by the Bhutan Power Corporation, it is assumed that only some parts of the 9FYP outlay earmarked for the Energy sector will be expended. 


\section{Profiling the Poor}

6.1 In order to facilitate focusing of policies and adopting of appropriate strategies in addressing the poverty, the analyzing of poverty incidences through, such as, profiling of poor would give a meaningful input. With this objective in mind, the Royal Government attempted carrying out some poverty studies such as HIES 2000 and PAA 2000.

6.2 While the HIES 2000 findings focused on the household level, the PAA 2000 results dealt with the situation at the block (Gewog) and district (Dzongkhag) levels. They complement each other. However, as is often the case with any surveys of this nature, the results should be taken as indicative until they are confirmed through more systematic surveys.

\section{Household Income and Expenditure Survey 2000 (Pilot)}

6.3 While the main objective of the HIES 2000 was to generate information for the compilation of national accounts for the household sector and the weights to be used in the consumer price index, the data were also used to make a preliminary analysis of the poverty situation in Bhutan. The HIES 2000 collected information on household income, expenditure, demographics and employment. Fieldwork for the HIES 2000 was conducted in only one round during April - June 2000, which partly overlapped with the lean months of May, June and July when food grain deficits are most severe in some parts of the country. As a result, the survey results may suffer from seasonal bias.

6.4 The information generated from the HIES 2000 show the average monthly per capita expenditure to be $\mathrm{Nu} 1,945$ in urban areas, $\mathrm{Nu} 928$ in rural areas and $\mathrm{Nu}$ 1,075 for the nation. Although Bhutan does not yet have an official national poverty line, the HIES 2000 defined lower and upper poverty lines. The lower poverty line is defined based on the expenditure of households whose total expenditure is adequate to meet the minimum food requirements and is estimated to be $\mathrm{Nu} 612.10$ per capita per month. It may be viewed as the food poverty line. The upper poverty line is defined based on the expenditure of households whose food expenditure is adequate to meet the minimum food requirements and is estimated to be $\mathrm{Nu} 748.10$ per capita per month. It may be considered as the income (absolute) poverty line.

6.5 The incidence of poverty was estimated using the two poverty lines (see Table 10). As the data in Table 10 shows, about one in four persons may suffer from food poverty while more than one in three suffer from income poverty. A poverty gap measure (the ratio or percentage of the amount required to bring the expenditures of the poor to the poverty line, relative to the total expenditures of the poor at the poverty line) is used to measure the intensity of poverty. The 
poverty gap is estimated to be $6.6 \%$ using the food poverty line and $11.1 \%$ based on the income poverty line.

Table 10: Poverty Incidence in Bhutan, 2000

\begin{tabular}{|c|c|c|}
\hline \multicolumn{1}{|c|}{ Item } & $\begin{array}{c}\text { Lower Poverty Line } \\
\text { (Food Poverty Line) }\end{array}$ & $\begin{array}{c}\text { Upper Poverty Line } \\
\text { (Income Poverty Line) }\end{array}$ \\
\hline Expenditure & $\mathrm{Nu} 612.10$ & $\mathrm{Nu} 748.10$ \\
\hline $\begin{array}{c}\text { Population Poor (\%) } \\
\text { Urban }\end{array}$ & 2.9 & 6.4 \\
Rural & 29.0 & 41.3 \\
Total & 25.3 & 36.3 \\
\hline Poverty Gap (\%) & 6.6 & 11.1 \\
\hline
\end{tabular}

\section{Bhutan Poverty Assessment and Analysis (Pilot)}

6.6 The main objective of the PAA 2000 was to assess the impact of Government policies and programs in improving the quality of life of the people. It was an attempt to construct a qualitative and quantitative database on selected living standard indicators covering both income and non-income dimensions at the Gewog (block) and Dzongkhag (district) levels. Ten living standard aspects were covered: household income, education, health, economic activities, non-material needs, physical facilities, environment, transport, communication and position of women. It was a nationwide survey covering all 201 Gewogs and 22 townships. The information was collected through questionnaire completed by the 20 Dzongdags (District Administrators) drawing upon existing information on facilities in the Dzongkhags and their perceptions on the living standards in their respective townships and Gewogs.

6.7 The results of the PAA 2000 indicated the priority needs of all Dzongkhags in descending order as follows: education, economic activities, household income, health, communication, physical facilities, transport, environment, women's position and non-material needs. It is important to keep in mind that the ranking of priority needs is relative within the ten indicators. For example, the nonmaterial needs and health are better served than those in education. Also, there are significant differences in the priority needs between Dzongkhags. For example, Pemagatshel and Samdrup Jongkhar districts (located in east southern) ranked transport and communication as the highest priorities (ranks 1 and 2) while Thimphu and Paro (located in western) ranked them at the lower end (ranks 8 and 9). Based on the PAA 2000 results, the Dzongkhags were ranked on the ten quality 
of life indicators and composite indices of these. The results show that the Dzongkhag of Gasa (west northern) was most vulnerable overall (at the bottom or 1 among the 20 Dzongkhags), followed by Pemagatshel (2), Lhuentse (located in the east) (3), Zhemgang (located in the central south) (4), with Trongsa (located in the Central) and Samdrup Jongkhar alternating in fifth and sixth places (see Table $11)$.

\section{Table 11: Ranking of Most Vulnerable Districts based on Composite Indices}

\begin{tabular}{|l|c|c|c|c|c|c|}
\hline \multicolumn{1}{|c|}{ Index/Item } & Gasa & Pemagatshel & Lhuentse & Zhemgang & Trongsa & $\begin{array}{c}\text { Samdrup } \\
\text { Jongkhar }\end{array}$ \\
\hline Overall Vulnerability & 1 & 2 & 3 & 4 & $5 / 6$ & $6 / 5$ \\
\hline Household Incomes & 1 & 4 & 7 & 2 & 6 & 3 \\
\hline Education & 1 & 2 & 6 & 7 & 3 & 14 \\
\hline Health & 6 & 2 & 4 & 9 & 10 & 1 \\
\hline Economic Activities & 2 & 4 & 7 & 1 & 5 & 3 \\
\hline Physical Facilities & 3 & 7 & 1 & 10 & 9 & 13 \\
\hline Environment & 3 & 7 & 2 & 8 & 15 & 5 \\
\hline Transport & 1 & 2 & 3 & 9 & 5 & 4 \\
\hline Communication & 5 & 2 & 10 & 1 & 4 & 6 \\
\hline Position of Women & 2 & 1 & 10 & 4 & 7 & 11 \\
\hline Non-Material Needs & 15 & 19 & 2 & 9 & 1 & 10 \\
\hline
\end{tabular}

Note: There are 20 Dzongkhags (districts) in the country and the ranks range from 1 (lowest) to 20 (highest).

Source: RGOB, Planning Commission, Bhutan: Poverty Assessment and Analysis Report 2000, Thimphu, November 2001.

6.8 The PAA 2000 also ranked the 50 vulnerable Gewogs, accounting for about $20 \%$ of the total number of households, from most vulnerable to least vulnerable. The results show that some of the most vulnerable Gewogs were to be found in some of the relatively well off Dzongkhags. For example, the second and third (or fourth) most vulnerable Gewogs of Naro and Soe were in Thimphu, which was the top ranked Dzongkhag. About 28 Gewogs comprising about $10 \%$ of the total number of households were ranked to be the most vulnerable. The study also tried to ascertain the geographic concentrations of the poor. About $75 \%$ of the households of the poorest (most vulnerable) Gewogs were to be found in Pemagatshel, Zhemgang, Mongar and Trashigang and Samdrup Jongkhar Dzongkhags.

6.9 Further, 63 of the 201 Gewogs and 22 townships report food insecurity; $65 \%$ of the Gewogs have no access to electricity; one-third of the Gewogs are not connected to feeder roads; and 45 Gewogs are below the national average for primary enrolment rate of $72 \%$. Two Dzongkhags account for the lowest level of modern sector economic activities. 


\section{Who are the poor}

6.10 The HIES 2000 generated information that helped to identify the poor. A large majority of the poor were employed in occupations that did not generate adequate income to fulfill their basic needs. Thus, the poor were engaged in subsistence production in farming and animal husbandry, petty trading, day labour and other vocations. Some of them were engaged in more than one occupation/job that did not generate adequate income to bring them over the poverty threshold. A small minority of the poor may be unemployed or cannot work due to age (very young and very old), disability or other constraints. The poor were more likely to be rural residents; many of them located in remote areas.

6.11 The characteristics of poor households are summarized in the following:

Rural areas:

- Subsistence farmers relying largely on crops,

- Larger families with a higher proportion of children and older people who cannot work (high dependency ratio),

- No or very few livestock,

- No or very little off-farm income including remittances, and

- Limited schooling.

Urban areas:

- Migrant household, living in hutments or shanties,

- Larger families with a higher proportion of children and older people who cannot work (high dependency ratio),

- Petty trader,

- Casual or day labourer.

\section{Where are they located}

6.12 About 79\% of the population is located in rural areas and the bulk of them depend on agriculture, including livestock and forestry, for their livelihood. The incidence of poverty in rural areas is more than five times than in urban areas $-41.3 \% \mathrm{vs}$. $6.4 \%$ (see Table 9). Extrapolation of the results from the HIES 2000 show that a large majority of the Bhutanese poor (about 96\%) live in rural areas. Thus, it may be fair to conclude that poverty in Bhutan is essentially a rural phenomenon. At the same time, the transmission of poverty in rural areas to urban centres through rural-urban migration is recognized. Spatially, the PAA 2000 findings show that the poor seem to be concentrated in the most vulnerable Gewogs spread all over the country. 


\section{Inequality and Poverty}

6.13 Data on inequality in expenditure distribution are presented in the HIES 2000. The Gini coefficient measuring the inequality in distribution of expenditure was estimated to be 0.36 for the nation. ${ }^{4}$ The inequality is higher in urban areas (Gini ratio of about 0.36 to 0.42 ) as compared to that in rural areas (about 0.35 ). This is considered moderate by both regional and global standards.

6.14 Factors contributing to the inequality in expenditure (income) in the rural areas include unequal ownership of or access to productive assets including land, irrigation, livestock, improved technology, human skills, and transfer payments (including remittances). Many of these factors are heavily influenced by the access to roads and transport, markets, communications and technology. In urban areas, the factors include unequal ownership of land and housing, economic enterprises and skills.

\section{Gender and Poverty}

6.15 There are no significant differences between women and men in the incidence of poverty. The ranking of Dzongkhags on their vulnerabilities on the position of women is largely the same as that on other dimensions, whilst some differences are evident. The exceptions are the rankings on the position of women for Trashiyangtse (rank 3 from the bottom), Trashigang (5) and Wangdue Phodrang (6), which are generally lower than their overall rankings on other dimensions, whereas that for Lhuentse (10) is significantly higher (PAA 2000).

\section{Causes of poverty}

6.16 The more apparent causes of poverty include the following:

- Remote location and difficult terrain that make access to outside world difficult. Lack of roads and transport networks, electricity and communications aggravate the situation. People in many poor communities may have to walk for 3 hours to a few days to reach the nearest highway;

- Limited ownership or access to productive assets including land. According to the 1988 National Agronomic Survey, 9\% of the farm households in the country owned less than half a hectare, $27 \%$ less than one hectare and $58 \%$ less than two hectares of land. Thus, many poor households may not own adequate land and/or a significant number of livestock;

- Lack of remunerative employment. Many poor households in rural and semi-urban areas have very few opportunities for off-farm employment;

- Large families and rapid population growth. For example, in rural areas where poverty is more severe, almost half (49\%) the households had an average of six or

\footnotetext{
${ }^{4}$ The inequality in income distribution is often larger than that in the distribution of expenditure.
} 
more members (HIES 2000). The rate of growth of the population was estimated to be about $3.1 \%$ in 1994 and it was projected to have declined to $2.5 \%$ in $2000 ;^{5}$

- Lack of productive skills. According to the HIES 2000, the adult literacy rate in rural areas, where the majority of poor are located, was $41.5 \%$ as compared to $75.9 \%$ in urban areas;

- Shortage of labour in some rural households due to migration of youth and working adults to urban centers leaving behind the very young and the very old;

- Lack of or limited access to social and economic services (including credit). A sizeable proportion of the rural communities lack easy access to schools and markets. In some communities, students have to walk for two to three hours each way to reach the nearest primary school;

- Natural calamities including floods, hailstorms, landslides, fires and wild animals;

- Social breakdown, including breakdown of marriage, family and social support systems;

- Increases in prices of basic goods and services; and

- Illnesses including diseases like Malaria, TB, and other ailments and deaths.

6.17 Some of the causes may be accentuated by poverty thereby creating a vicious circle. The symptoms of poverty include inability to own a decent house, vulnerability to food shortages, and lack of sufficient funds to send children to school.

\section{Poverty Reduction Challenges and Strategies}

7.1 The challenges for poverty reduction include the lack of or limited opportunities to increase incomes, limited access to basic services like marketing, vulnerability to natural and man-made shocks including food insecurity, limited access to information and civic education, and lack of well defined poverty indicators and monitoring mechanisms.

7.2 The development plans and strategies in Bhutan have always recognized the need to address the needs of the poor and other vulnerable groups. The development philosophy of enhancing Gross National Happiness provides a sound overall framework for poverty reduction. Given that poverty in Bhutan is predominantly a rural phenomenon, comprehensive rural development programs supported by adequate infrastructure (including social infrastructure), private sector-led income and employment generation and good governance will remain integral parts of the overall strategy for reducing poverty in the Ninth Plan. The Government visualizes sustainable poverty reduction to be achieved through rapid and equitable economic growth with balanced regional development. Macroeconomic management including the pattern of public expenditures will continue with a clear pro-poor orientation. Many essential elements of poverty reduction are

\footnotetext{
${ }^{5}$ RGOB, Central Statistical Organization, Statistical Yearbook of Bhutan, 2001, Thimphu, November 2001. The population growth rate seemed to have moderated to $2.5 \%$ by 2001 .
} 
incorporated in the sector strategies. An attempt is made in the following to link the various sector strategy elements to tackling the poverty reduction challenges.

\section{Opportunities to Increase Incomes}

\section{Challenges}

7.3 The challenges include increasing the incomes of the people in general and the poor in particular, through remunerative jobs and sustainable livelihoods. As a large majority of the poor live in rural areas and most of them depend on agriculture, improving their productivity will be an important means to increasing their incomes. However, they face several constraints, including (i) small size of land holding and few livestock per household, (ii) lack of irrigation, (iii) limited or lack of access to modern technologies and inputs, (iv) lack of or limited offfarm employment opportunities, and (v) limited access to markets and high transport costs.

7.4 The extension of irrigation requires substantial investments as well as new skills to practice irrigated agriculture. Also, the small size of holdings makes the feasibility of mechanization difficult. The lack of adequate farm and feeder roads contribute to the limited access to modern technologies and inputs as well as markets. In fact, inadequate physical access is perhaps the single most important challenge facing the poor in many Gewogs with concentrations of the poor. This is also a serious impediment to not only increasing productivity in agriculture but also the development of off-farm enterprises and jobs. Thus, a number of off-farm enterprises and employment creation initiatives promoted by the Government in cooperation with civil society organizations have not generated the expected benefits due to the high costs of production and marketing resulting from poor physical access.

\section{Strategies}

7.5 Some of the salient strategies and interventions proposed under the Ninth Plan include the following:

- Considering that a large majority of the poor are dependent on agriculture, the sector strategy focuses on improving productivity through land reforms, introduction and adoption of modern farming and animal husbandry practices, expansion of irrigation, facilitating diversification into high value, low-bulk crops and products, increasing access to credit, promotion of cooperatives, constructing and improving farm and feeder roads and market infrastructure, enhancing the flow of information and communications, promoting sound and sustainable management of the natural resources, and providing an enabling policy and legal framework;

- Promotion of off-farm enterprises and opportunities to reduce the pressure on the limited arable land and generate employment and sustainable livelihoods in the 
rural areas through access to training, technical assistance, productivity enhancing technologies, credit, and markets for inputs supply and sale of outputs, which again hinge critically on easy physical (road) access and rural electrification;

- Creating an enabling environment for the private sector including more transparent industrial and investment policies and supporting laws, as well as development of industrial estates and service centers. In the medium and longterm, private sector is expected to be the engine of economic growth and employment generation to cater to the burgeoning labour force including the youth. Improvements in infrastructure including roads and transport, electricity and communications are equally important for encouraging private investments, enhancing the competitiveness of Bhutanese products in regional and global markets, and creating remunerative jobs;

- Enhancing the skills of the workforce including the youth through technical and vocational training, in partnership with potential employers, as well as adjusting the school curricula to impart more life skills for the graduates to be entrepreneurs in different sectors; and

- Improvements in and expansion of infrastructure including roads (in particular, construction of more than $500 \mathrm{kms}$ of new farm roads, $123 \mathrm{kms}$ of feeder roads and completion of $46 \mathrm{kms}$ of feeder roads), electricity including rural electrification, and communications including telecommunications, radio and television services, especially to the hitherto un-served and underserved areas, which are critical for encouraging private entrepreneurship and investments, and promoting equity and balanced regional development.

\section{Access to Basic Social Services}

\section{Challenges}

7.6 The access to health services and education, especially in rural areas, improved considerably during the past 15 years. Thus, the coverage of immunization of children has reached above $90 \%$. In general, access to health services improved more rapidly. Notwithstanding, trained health personnel attended less than one-infour births. Low birth weight continues to be a problem in about one-in-four newborns. Access to hospitals continues to be difficult in some Dzongkhags that lack adequate road and transport infrastructure.

7.7 While access to primary schooling has also increased, with the primary gross enrolment rate exceeding $81 \%$ in 2003 , the net enrolment rate is lower and there is still considerable room for improvement. Some children may still need to walk between two to three hours each way to the nearest school, often through rugged terrain including forests. As a result, parents tend to defer enrolment of youngsters at the primary entry age of 6 years and do so at 7, 8 or 9 years after the children have gained adequate physical stamina to keep up with the long and arduous daily commute. Again, physical access (feeder roads and tracks) seems to be the main constraint. Further, many poor families cannot afford the costs of school uniforms, supplies and transport costs. 
7.8 Access to safe water has increased considerably over the years, with about $78 \%$ of the population having safe drinking water close to their communities. In the remaining communities, women and children have to walk long distances to fetch water from streams and springs. The coverage of basic latrines or sanitation facilities is much higher at about $88 \%$ of the total population. Most urban poor seem to be found in hutments in informal settlements or squatter areas. Access to basic services (e.g. water and sanitation) for many of these households is difficult. As in the generation of opportunities for increased income, the efficient delivery of basic social services to the hitherto unreached and underserved depend critically on significant improvements in road and transport networks, rural electrification and communications.

\section{Vulnerability Including Food Insecurity}

\section{Challenges}

7.9 Vulnerability may be due to unforeseen calamities including diseases/illnesses, death, floods, landslides, hailstorms, fires and droughts. One of the major risks faced by a significant proportion of Bhutanese families relates to seasonal shortages of food or food insecurity. Thus, according to a Food Security Survey, about $39 \%$ of households in Pemagatshel District suffered chronic food insecurity, while the proportion was $19 \%$ in Lhuentse district. ${ }^{6}$ Results from the 1999 Nutrition Survey indicate that on average, children from some pockets of Eastern Bhutan were nutritionally worse off than those from other regions.

7.10 Food insecurity results from low land holdings, low productivity, localized disasters such as hailstorms, strong winds, fungal diseases, damage by wild animals including mammalian pests and birds. Usually, food grain deficits are seasonal (mainly from May to July) with a significant number of households in the community facing the same burden. To make matters worse, the food deficit months coincide with the periods of intensive agricultural operations including tilling and planting when the food needs of the workers are higher than normal. The effect on children is partly alleviated through school feeding projects supported by the World Food Programme.

\section{Strategies}

- The close kinship and traditional social support systems based on Buddhism, which emphasizes the interdependence of all members of society while promoting individual development, have helped families and communities to cope with vulnerabilities.

- Food insecurity is largely related to deficits in rice and edible oils and fats. It has been identified as one of the major problems facing a significant proportion of the

\footnotetext{
${ }^{6}$ Cited in UNICEF Bhutan, A Situation Analysis of Children and Women in Bhutan, 2000, Thimphu.
} 
people. The country is self sufficient in rice to the tune of $60 \%$ of its requirements. Those with adequate incomes (e.g. from sale of cash crops, wage labour and remittances) fill their food deficits through purchases from the Bhutan Food Corporation. The poor and low-income households cope with rice/food shortages through a shift to other cereals like maize, roots and forest products, and/or a reduction in consumption. The national policy objective is to attain food security through a two-pronged strategy: (i) increase production of cereals to achieve at least $70 \%$ self-sufficiency, (ii) promote expansion of agricultural production including cash crops for export to finance the additional food imports. Self-reliance is the ultimate goal.

\section{Poverty Monitoring and Assessment}

8.1 Poverty monitoring and assessment at present is carried out by a range of actors at different administrative levels using different systems and on an ad hoc basis. This has created problems of coordination, systematic use of data and impact assessment. The government recognizes the need to streamline the system and to institutionalize Poverty Monitoring and Assessment System (PMAS) and has identified the Department of Planning as the focal agency responsible for poverty monitoring and assessment. The proposed PMAS will be integrated and built-in within the overall Planning and Information Network (PIN) system being developed in the Department of Planning.

\section{Box 2: List of Surveys Completed}

The National Labour Force Survey (NLFS) 1998 \& 1999, 2001, $2003 \& 2004$ and which provides data on unemployment, underemployment and participation rates;

The National Nutrition Survey (NNS) 1999, which collected anthropometrics data, used to calculate malnutrition levels;

The National Health Survey (NHS) 2000, which provides data on health;

The Renewable Natural Resources Census (RNRC) 2000, which provides data on landholdings and rural assets;

The Pilot Household Income and Expenditure Survey (HIES) 2000 which contained detailed income and consumption modules allowed for the determination of poverty correlates, including dependency ratios, employment patterns, and educational achievements;

The Poverty Assessment and Analysis Report (PAAR) 2000 which presented community level data on a number of dimensions of well-being including education, health, environment, communications etc.;

The Bhutan Urban Poverty Study (BUPS) 2001, which presents information on urban poverty in Thimphu and Phuentsholing (yet to be endorsed by the government).

The Bhutan Living Standards Survey (BLSS) 2003 completed recently and expected to provide information on health and education as well as a detailed consumption module which will facilitate the determination of poverty and inequality indicators and poverty proxies.

8.2 The core problem is not a lack of data (though there are existing data gaps) as it is a lack of coordination of the many data collection exercises undertaken. Three types of coordination failure have been identified: 
- Lack of Coordination of Surveys and Censuses: There is no national statistics plan which identifies and sequences the major surveys to be conducted over the medium term. Most recent household surveys have been ad hoc and dependent on the availability of donor financing. As a result, sequencing has been less than optimal. For example, in 2000 alone approximately four significant surveys were conducted (see Box 2). Moreover, the Bhutan Living Standards Survey was conducted in 2003, prior to a proposed population census (it would obviously be preferable to reverse this order of events). A national statistical plan which identifies and sequences surveys would be one way of addressing these problems.

- Lack of Coordination between M\&E Systems across Ministries: A number of line Ministries have established, or are in the process of establishing, M\&E systems. Good examples include the M\&E framework for the RNR sector as well as the Health Sector Management Information System. While there are obvious sector-specific issues to address, it would be optimal for national planning and monitoring purposes to standardize a number of categories of indicators across sectors (e.g., using an input/output/outcome schema). This would facilitate more direct performance monitoring across ministries and direct incorporation of line ministry data into a 'poverty program' monitoring database. However, the DoP is working on a national level Monitoring and Evaluation System that will also have a link with the M\&E systems developed in various government agencies.

- Lack of Coordination of Reporting Frameworks at Dzongkhag Level: At the Dzongkhag level, there is a bewildering array of reporting frameworks used by different agencies. Different reporting formats are required for individual donor agencies, line Ministries, the Ministry of Finance and the Department of Planning. The result is reporting fatigue whereby valuable resources are devoted to completing forms rather than to operational activities. It would be optimal to agree upon a standardized reporting framework for completion at the Dzongkhag level which contains the requisite data to satisfy all the requirement of the different actors. However, the proposed M\&E system in DoP is expected to address this problem once it is completed.

- Lack of Systematic Use: There appears to be a lack of systematic use of monitoring-related data for policy purposes. Monitoring data on outputs or outcomes does not appear to influence budgetary allocations from year to year, which depend mainly on the ability to implement (i.e. to disburse committed funds). In the context of decentralized planning, it will be even more critical to put in place systems whereby resource allocation decisions reflect plan objectives as well as systematic assessment of program performance. These considerations suggest an extremely important role for the communication/advocacy component of the system as well as an appropriate 
institutional framework which ensure that information reaches policy makers, planners and implementers.

- Lack of Impact Assessment: Impact assessment differs from standard project monitoring and evaluation in that it is concerned with outcome or impacts which it attempts to link to program outputs. In this sense of the term, there does not appear to be any systematic process of impact assessment of programs or policies. However, the DoP has initiated the process and has already done an impact assessment of rural roads on rural poverty on a pilot basis in 2003. The process will continue on a regular basis for selective development programmes.

\section{Proposed Poverty Monitoring and Assessment System (PMAS)}

8.3 With a primary objective to coordinate, consolidate and harmonize data from existing poverty monitoring systems to produce concrete, timely and useful information and analysis for decision-makers, and to communicate results in ways which feedback into the policy process, the DoP proposes to set up a Poverty Monitoring and Assessment System (PMAS) within the department. However, for the time being, the system will be built within the Planning Information Network (PIN) system that is being established in the DoP.

\section{Principles of PMAS:}

8.4 National Ownership/Appropriation: System of poverty monitoring and analysis do not work in the absence of 'buy-in' from data users within and outside government. The process of data collection, analysis and use is likely to be as, or more, important than the physical outputs generated (indicators, data, etc.). This calls for concerted attempts to actively involve stakeholders in processes of data collection, analysis, dissemination and review. Therefore, the PMAS is proposed to be institutionalized within national structures to ensure its appropriation and usefulness. .

8.5 Participation: There are a number of reasons why widespread participation of a range of stakeholders in the operation of the PMAS is likely to be instrumental to its success. Specifically:

- it builds and strengthens capacities for analysis, discussion, and linking data generation to

- analysis and policy formulation, policy outcome monitoring and evaluation;

- it allows for genuine monitoring of development policies, strategies and programs on the basis of views of people affected by them;

- Above all, genuine participation helps build broad-based national ownership, a key ingredient in sustainable poverty eradication and human development strategies. 
8.6 Harmonization/Consolidation: As discussed, there is a significant amount of data on poverty in Bhutan as well as a wide range of policies and programs whose central objective is to reduce it. A core function of the unit will be to synthesis existing studies on poverty and store/consolidate the many types of data which bear on it. This provides the rationale for developing poverty-related databases linked to the Planning Information Network (PIN) system. Part of the work of the unit will consist of coordinating and harmonizing the many different systems of relevance to poverty monitoring in the country.

8.7 Collaborative Engagement: The PMAS will seek to form partnerships with persons and organizations engaged in poverty monitoring or other analytical work related to poverty. This pertains to governmental agencies, civil society organization and the international community. A major rationale of this policy framework document is to provide a mechanism to build partnerships with a view to improve coordination in poverty monitoring.

\subsection{The PMAS has five key components:}

- Component I - Poverty, Vulnerability and Inequality (PVI) outcome monitoring;

- Component II - Poverty Reduction Strategy (PRS) implementation monitoring;

- Component III - Impact Assessment and Policy Analysis;

- Component IV - Poverty Information Management;

- Component V - Communication/Dissemination.

\section{Component I - Poverty, Vulnerability and Inequality (PVI) Outcome Monitoring}

8.9 An important element of the Poverty Monitoring System is a comprehensive set of national poverty indicators. This component will comprise systems to track changes in poverty and well being at the outcome level. To this end, the DoP is in the process of finalizing a list of PVI indicators which is attached as Table 12. This list of indicators, which was prepared in consultation with concerned sectors and Dzongkhags in national workshops, will be reviewed periodically and revise, if necessary, with change in situation and requirement. Further, the first Bhutan Living Standards Survey (BLSS) 2003 has been recently completed which is an integrated household survey and complements the Participatory Poverty Assessment (PPA) conducted in 2000 on the population's perceptions of poverty and well-being and falls within component I. 


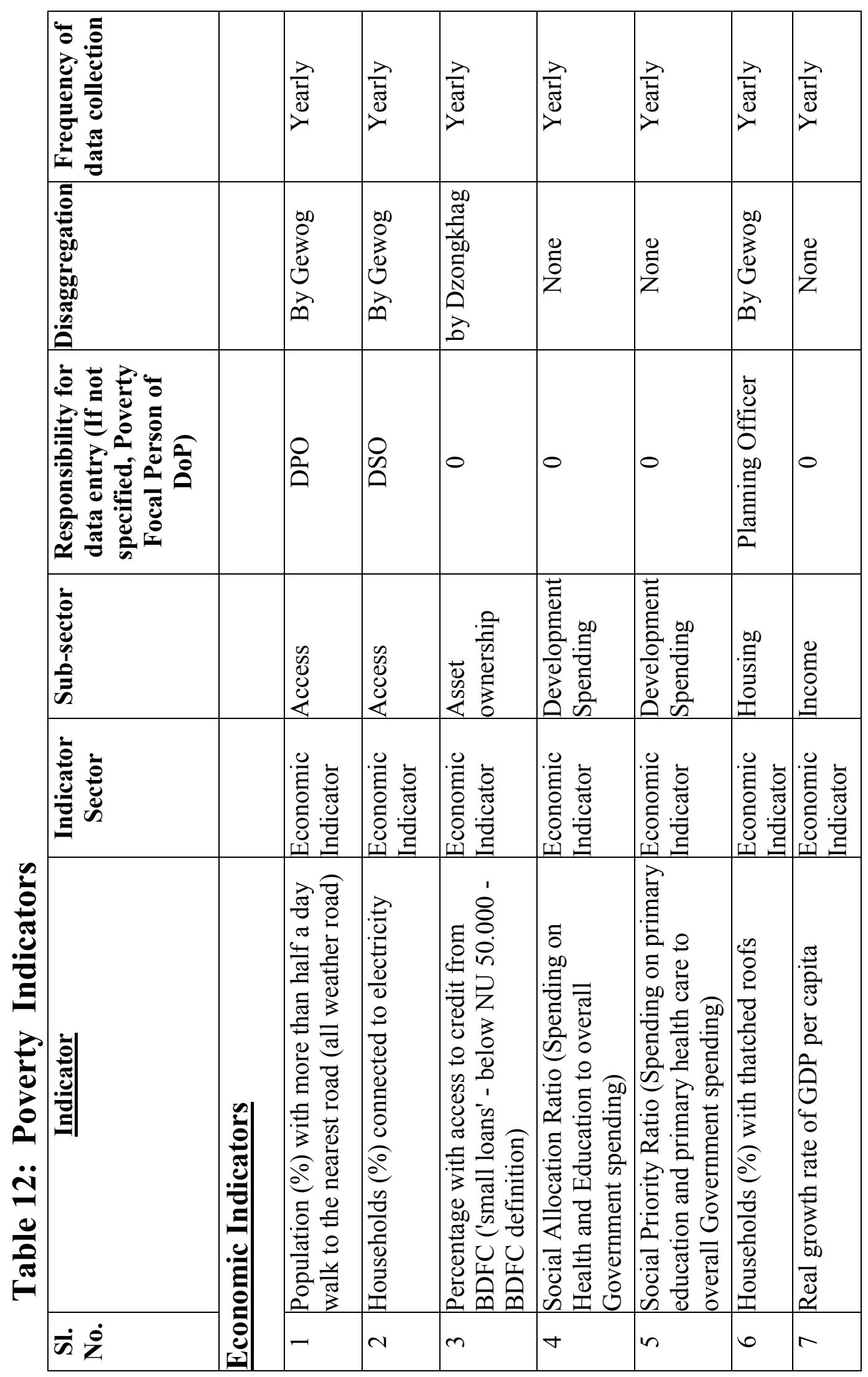




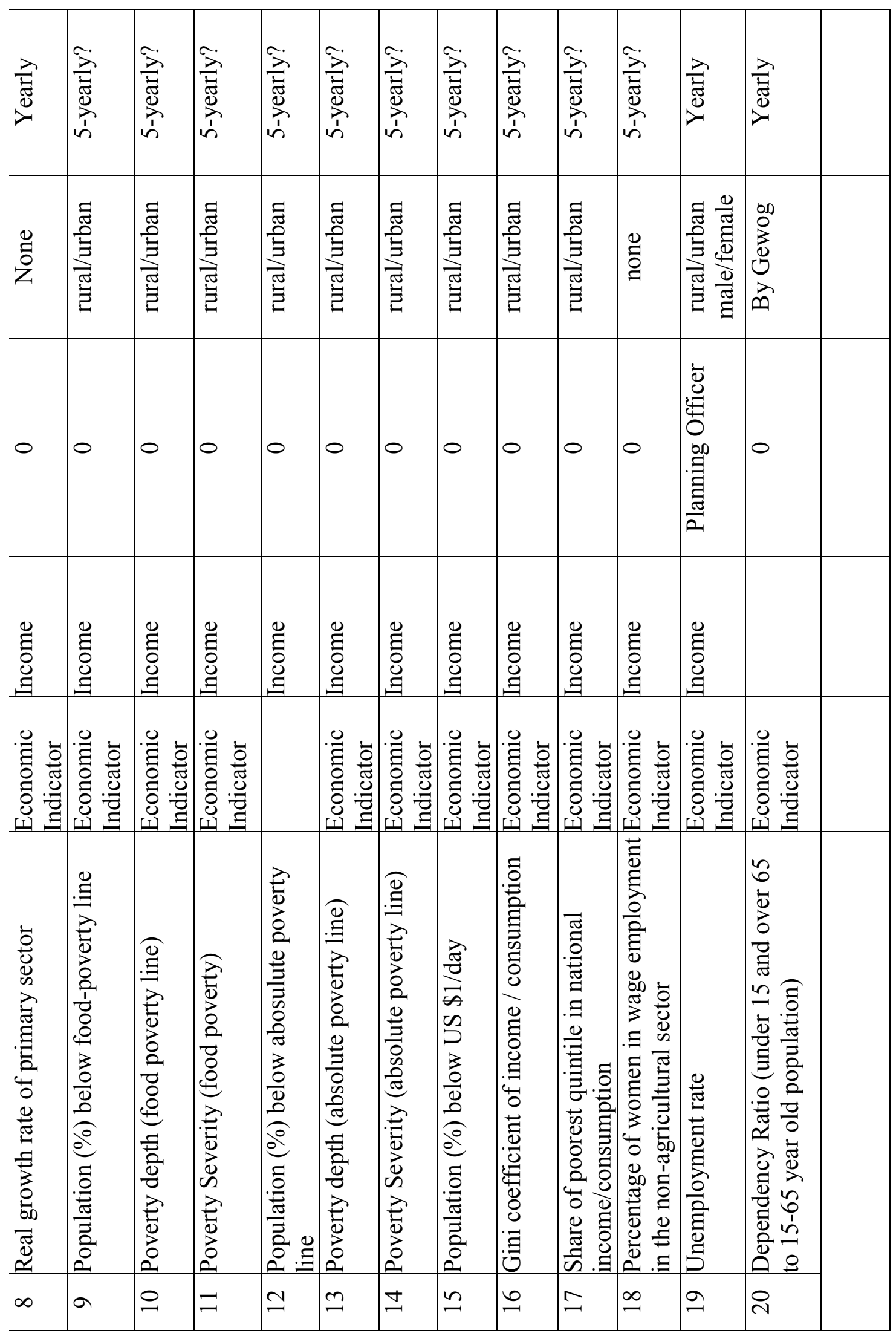




\begin{tabular}{|c|c|c|c|c|c|c|c|c|c|c|c|c|}
\hline & 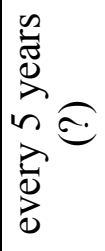 & 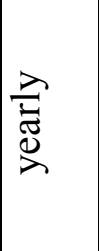 & 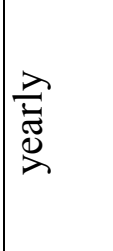 & 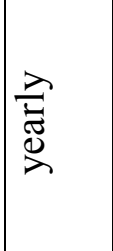 & 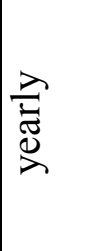 & 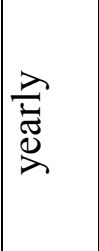 & 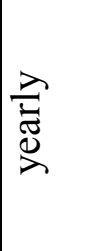 & 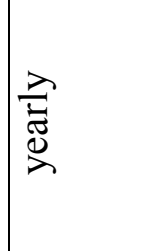 & 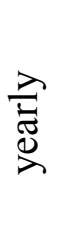 & 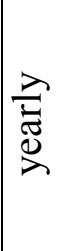 & 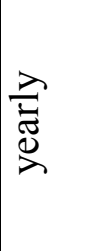 & \\
\hline & 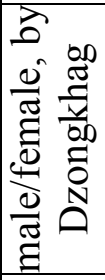 & 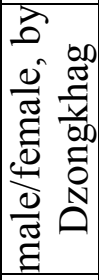 & 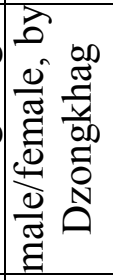 & 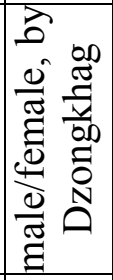 & 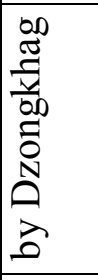 & 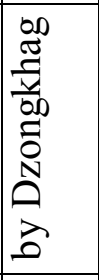 & $\begin{array}{l}\frac{n}{2} \\
0 \\
0 \\
0 \\
0 \\
0 \\
0 \\
n\end{array}$ & 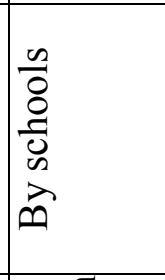 & 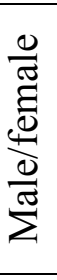 & 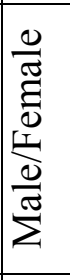 & $\begin{array}{l}0 \\
0 \\
0 \\
0 \\
0 \\
0 \\
0 \\
0\end{array}$ & \\
\hline & 10 & 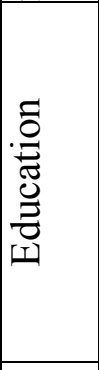 & . & 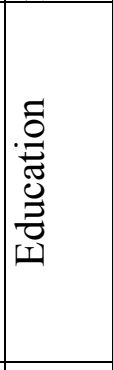 & 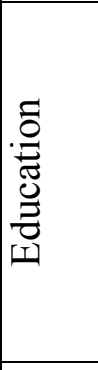 & 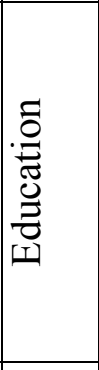 & 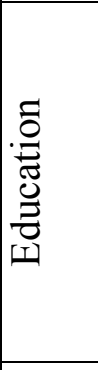 & 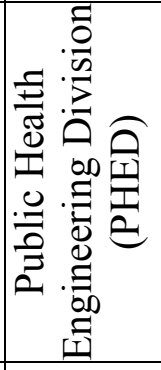 & 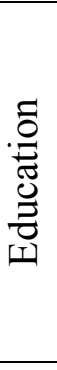 & 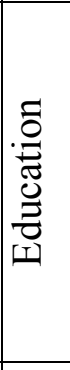 & . & \\
\hline & 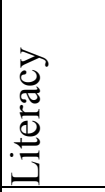 & 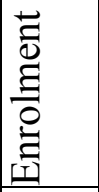 & 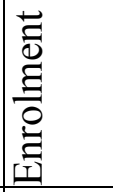 & 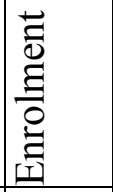 & 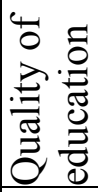 & 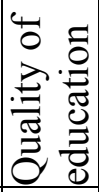 & 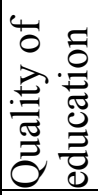 & 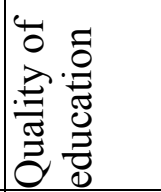 & 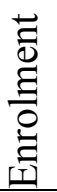 & 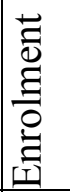 & 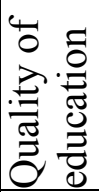 & \\
\hline & 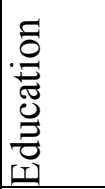 & 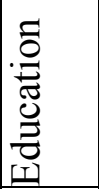 & . & 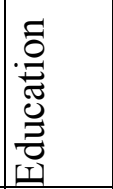 & 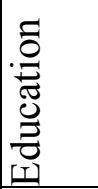 & 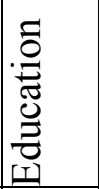 & 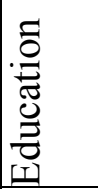 & 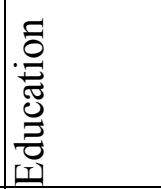 & 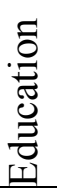 & 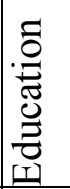 & 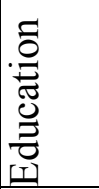 & \\
\hline \multirow[t]{2}{*}{ 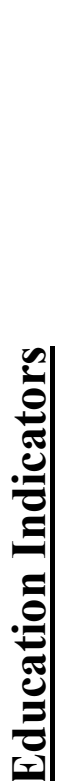 } & 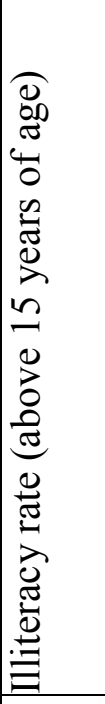 & 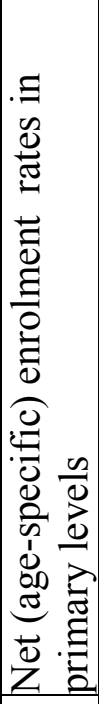 & 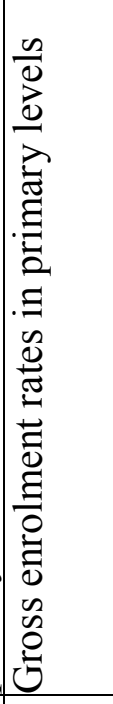 & 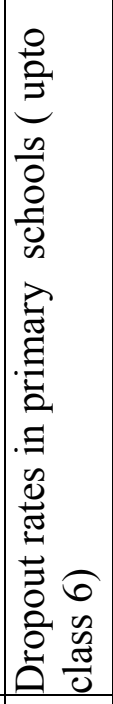 & 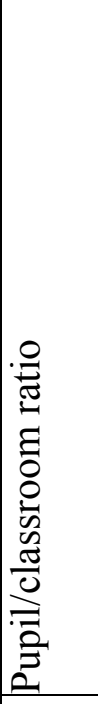 & 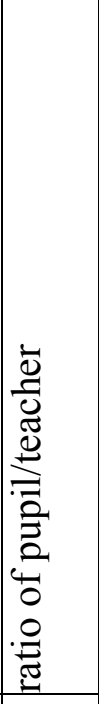 & 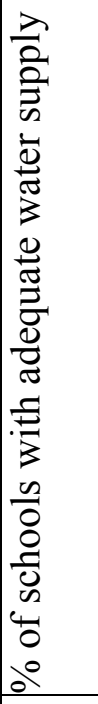 & 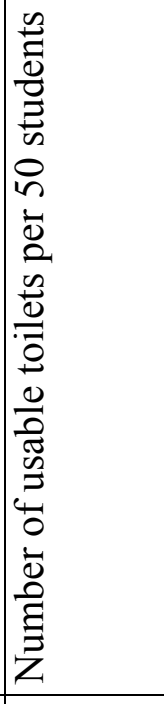 & 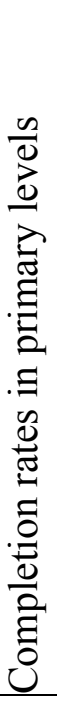 & 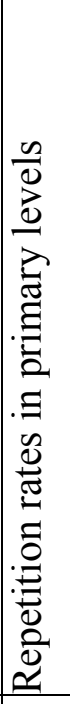 & 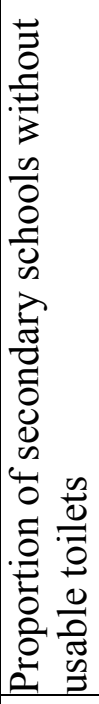 & \\
\hline & - & $N$ & $m$ & $\nabla$ & $n$ & 6 & $r$ & $\infty$ & $a$ & $\stackrel{\varrho}{ }$ & 二 & \\
\hline
\end{tabular}




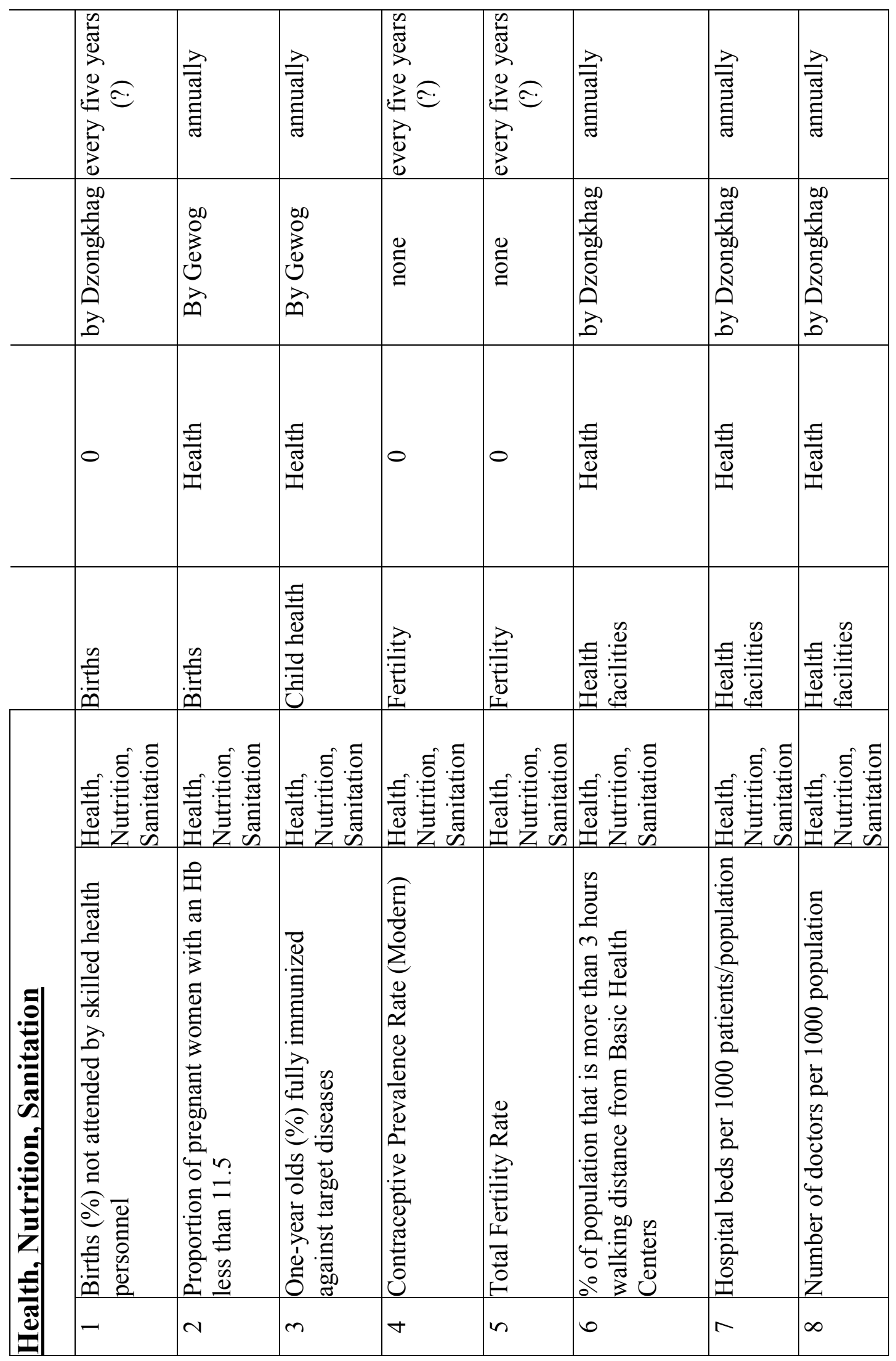

$\frac{\infty}{\forall}$ 


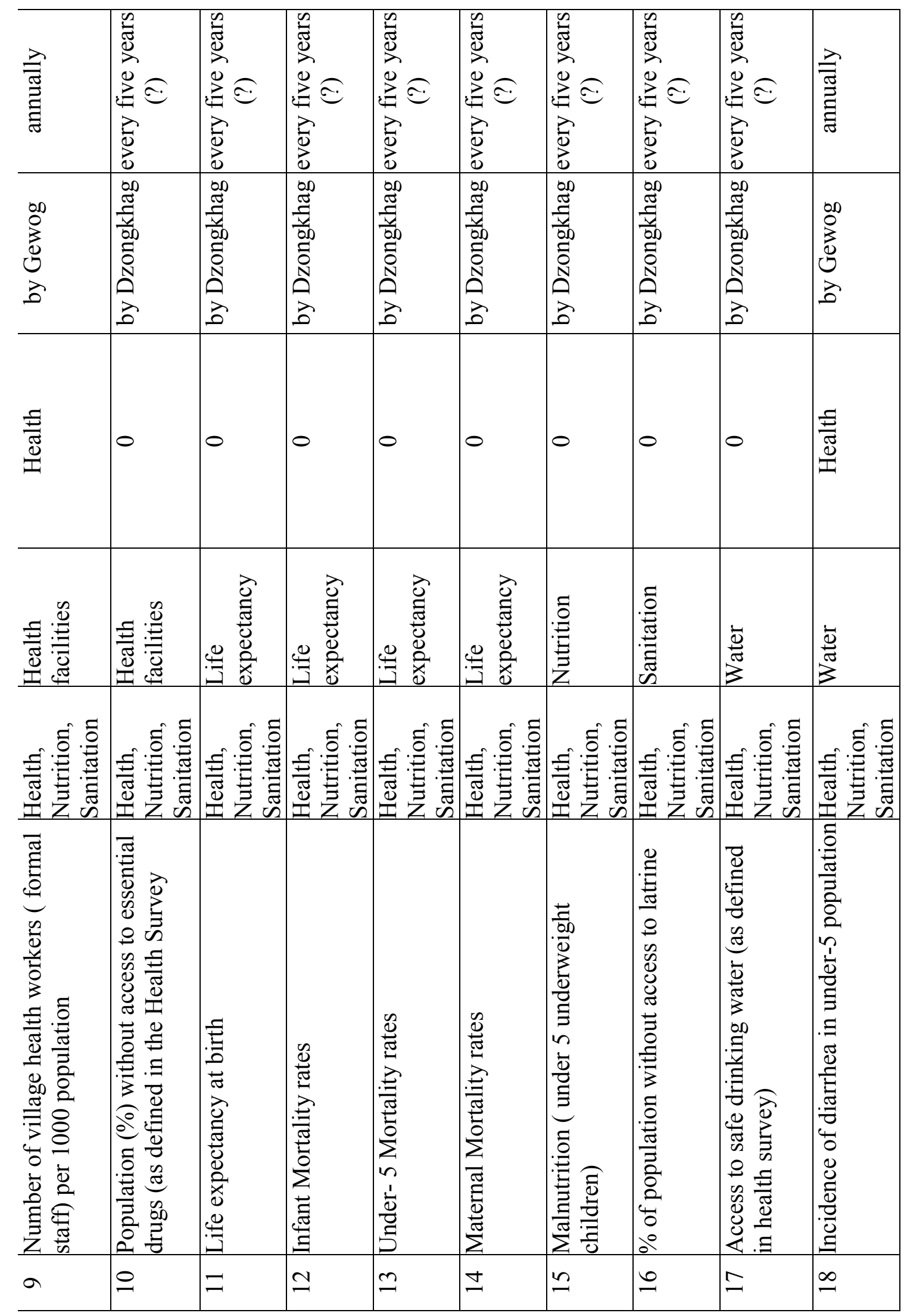

$\frac{9}{+\infty}$ 


\begin{tabular}{|c|c|c|c|c|c|c|c|c|c|c|c|}
\hline & 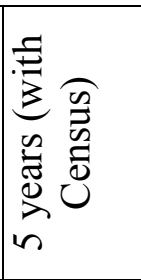 & 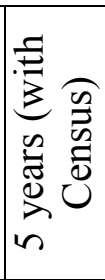 & 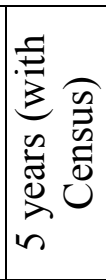 & 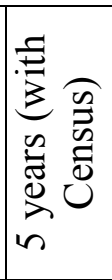 & 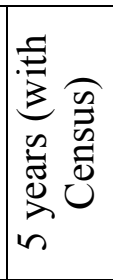 & 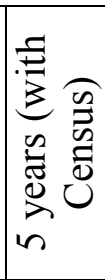 & 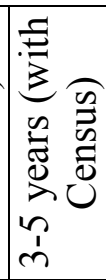 & 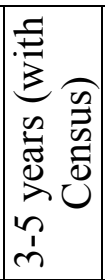 & 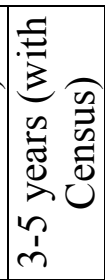 & 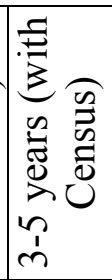 & 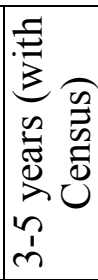 \\
\hline & $\begin{array}{l}0 \\
0 \\
0 \\
0 \\
0 \\
0 \\
0 \\
0 \\
0\end{array}$ & $\begin{array}{l}0.0 \\
0 \\
0 \\
0 \\
0 \\
0 \\
0 \\
0\end{array}$ & $\begin{array}{l}0.0 \\
0 \\
0 \\
0 \\
0 \\
0 \\
0 \\
0\end{array}$ & $\begin{array}{l}0 \\
0 \\
0 \\
3 \\
0 \\
0 \\
0 \\
0\end{array}$ & $\begin{array}{l}0.0 \\
0 \\
0 \\
0 \\
0 \\
0 \\
2 \\
0\end{array}$ & $\begin{array}{l}0.0 \\
0 \\
0 \\
0 \\
0 \\
0 \\
0 \\
0\end{array}$ & $\begin{array}{l}0 \\
0 \\
0 \\
0 \\
0 \\
0 \\
2 \\
0\end{array}$ & $\begin{array}{l}0.0 \\
0 \\
0 \\
0 \\
0 \\
0 \\
0 \\
0\end{array}$ & $\begin{array}{l}0 \\
0 \\
0 \\
0 \\
0 \\
0 \\
0 \\
0\end{array}$ & $\begin{array}{l}0 \\
0 \\
0 \\
3 \\
0 \\
0 \\
0 \\
0\end{array}$ & $\begin{array}{l}0 \\
0 \\
0 \\
0 \\
0 \\
0 \\
0\end{array}$ \\
\hline & 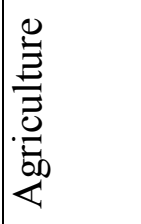 & 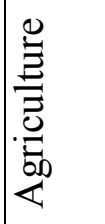 & 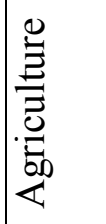 & 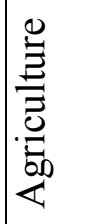 & 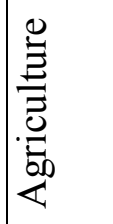 & 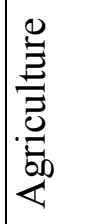 & 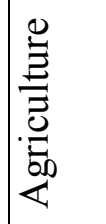 & 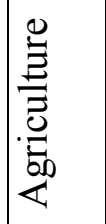 & 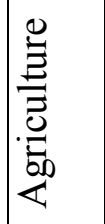 & 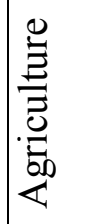 & 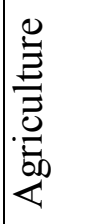 \\
\hline & 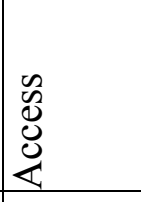 & 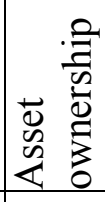 & 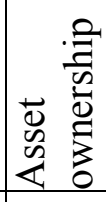 & 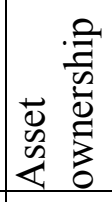 & 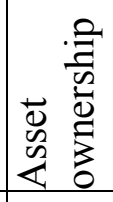 & 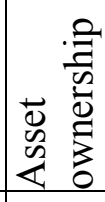 & 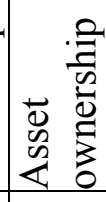 & 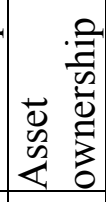 & 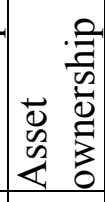 & 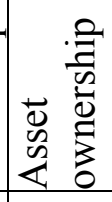 & 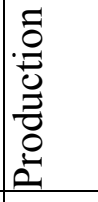 \\
\hline \multirow{3}{*}{ 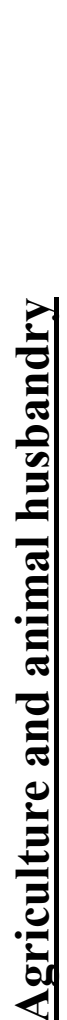 } & 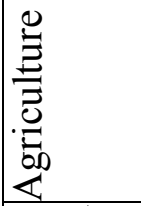 & 异 & 异 & 兽 & 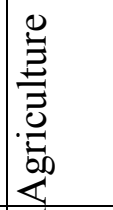 & 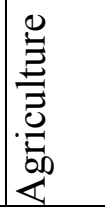 & 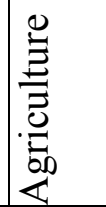 & 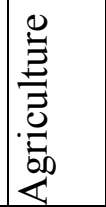 & 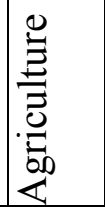 & 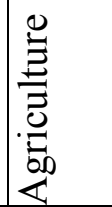 & 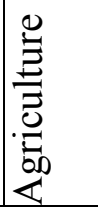 \\
\hline & 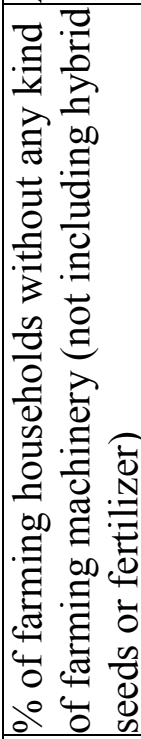 & 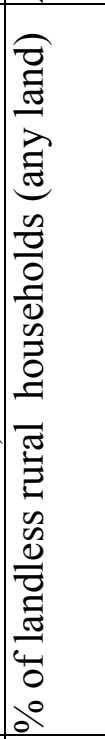 & 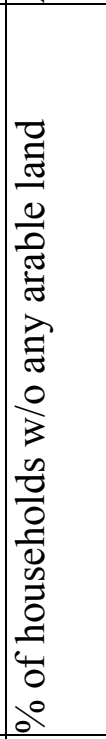 & 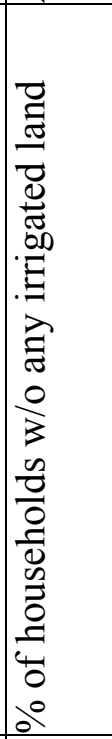 & 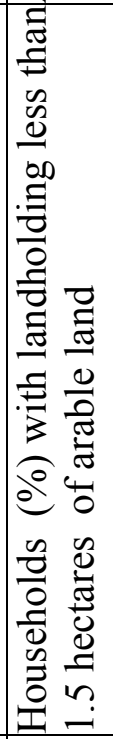 & 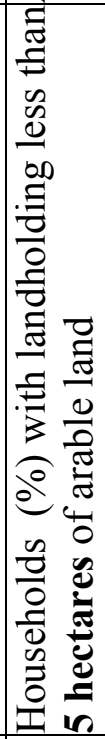 & 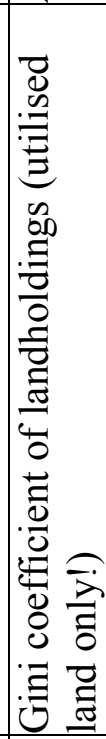 & 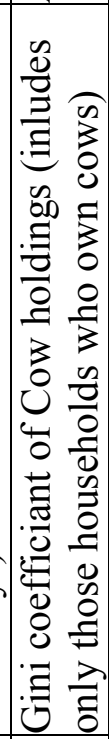 & 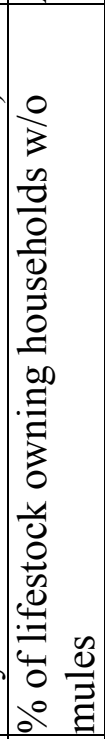 & 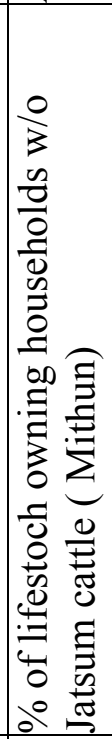 & 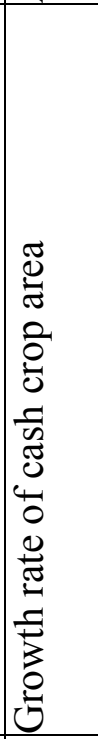 \\
\hline & 年 & $N$ & $m$ & $\nabla$ & in & 6 & $r$ & $\infty$ & $a$ & 0 & 二 \\
\hline
\end{tabular}




\begin{tabular}{|c|c|c|c|c|c|c|c|c|c|c|c|c|}
\hline 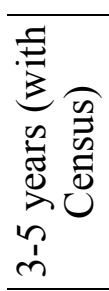 & 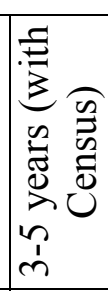 & 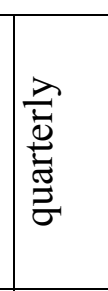 & 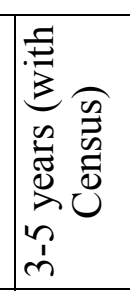 & & 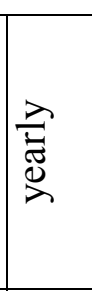 & 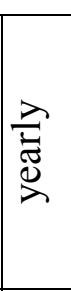 & 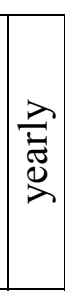 & & 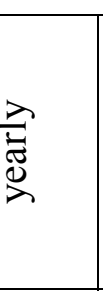 & 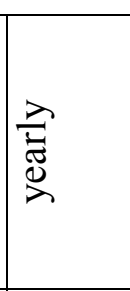 & & 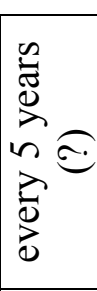 \\
\hline $\begin{array}{l}00 \\
0 \\
0 \\
0 \\
0 \\
0\end{array}$ & \begin{tabular}{|l}
$\mid c 0$ \\
0 \\
0 \\
0 \\
0 \\
0 \\
0
\end{tabular} & 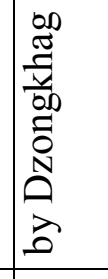 & \begin{tabular}{|l}
$\mid \infty$ \\
0 \\
0 \\
0 \\
0 \\
0 \\
0
\end{tabular} & & 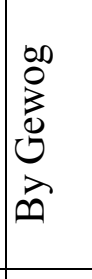 & 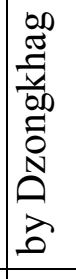 & 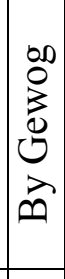 & 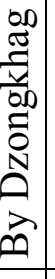 & 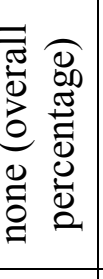 & 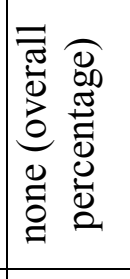 & & 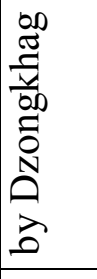 \\
\hline 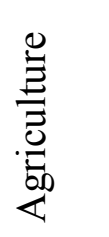 & 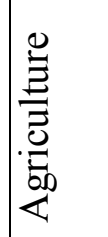 & $\overline{\tilde{z}}$ & 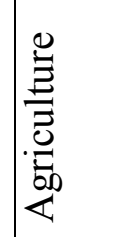 & & 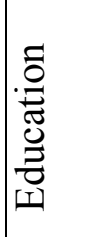 & 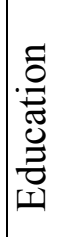 & 0 & 0 & 0 & 0 & & 0 \\
\hline 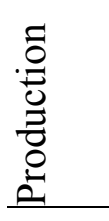 & 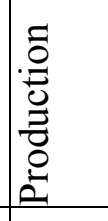 & 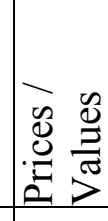 & 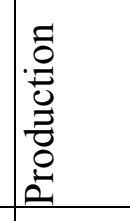 & & & & & & & & & \\
\hline 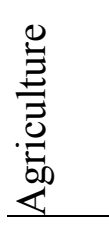 & 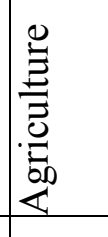 & 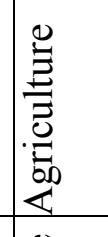 & 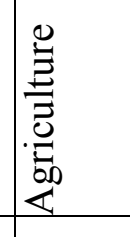 & & 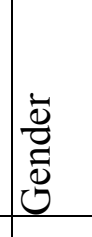 & 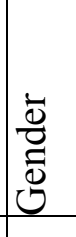 & $\begin{array}{l}\frac{\tilde{z}}{\tilde{z}} \\
\overline{\tilde{z}}\end{array}$ & & 离 & 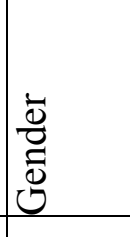 & & $\underline{\underline{U}}$ \\
\hline 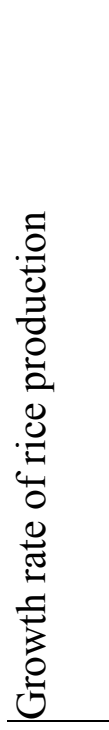 & 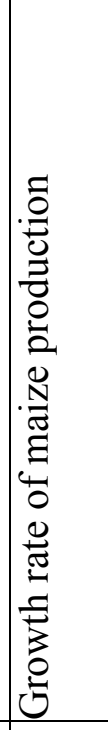 & 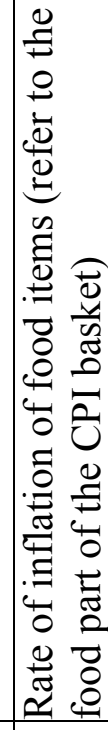 & 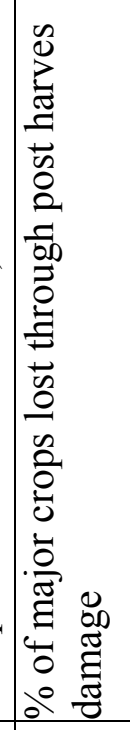 & & 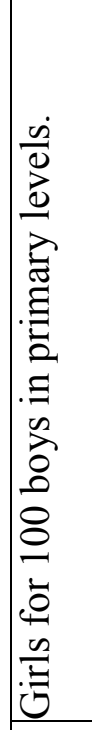 & 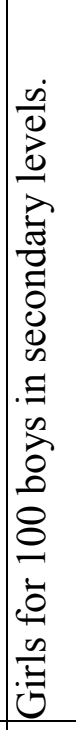 & 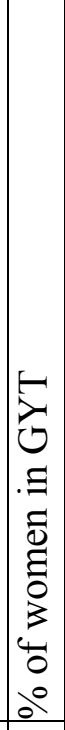 & & 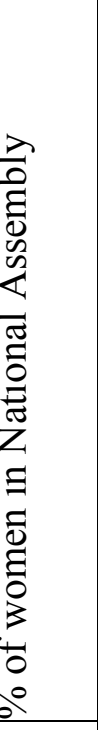 & 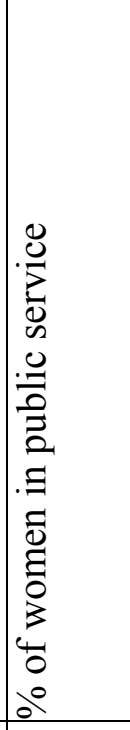 & & 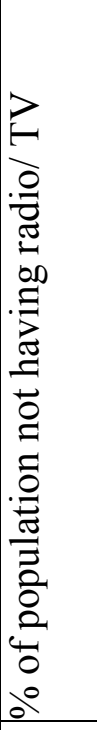 \\
\hline$\simeq$ & $m$ & \pm & $\cong$ & : & - & $\sim$ & m & $\nabla$ & in & 6 & & - \\
\hline
\end{tabular}




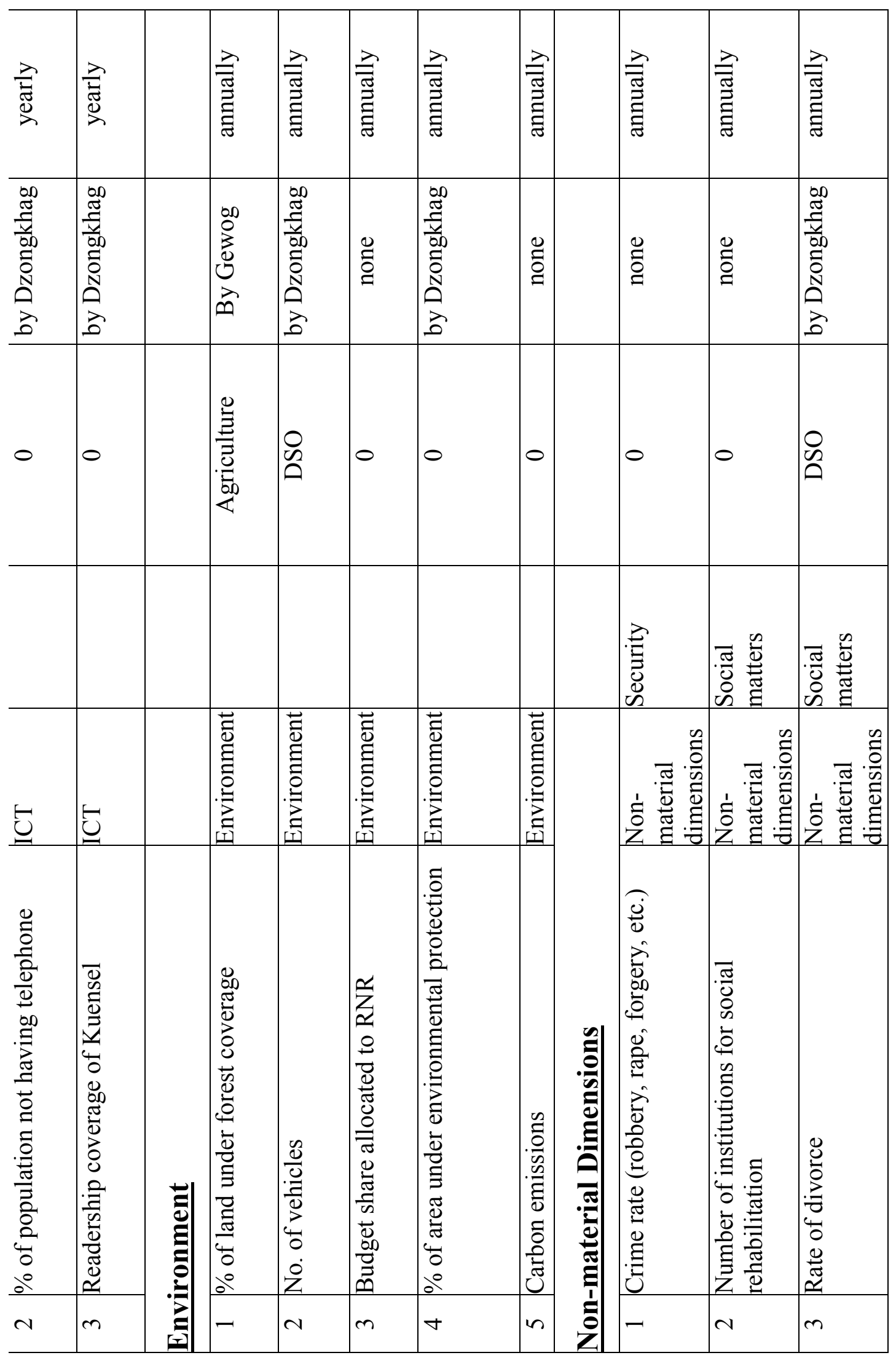

$\frac{n}{n}$ 


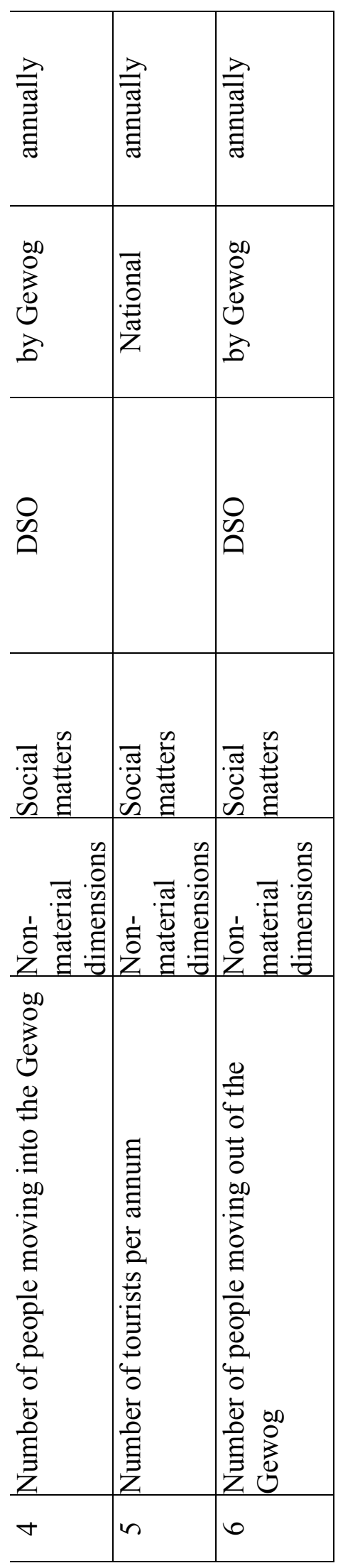

$\frac{n}{n}$ 



\section{Component II - Poverty Reduction Strategy (PRS) Implementation Monitoring}

8.10 The PRS Implementation Monitoring system will track inputs and outputs of poverty reduction programs and thus draw heavily on routine administrative monitoring data. To facilitate this, efforts will be made to harmonize the existing monitoring and evaluation systems including those already developed in other line ministries.

\section{Component III - Poverty Impact Assessment \& Policy Analysis}

8.11 Impact assessments establish a link between the outcomes/impacts analyzed in the PVI Monitoring System and the programs in the PRS Implementation Monitoring System. As a beginning of the process, a pilot Policy Impact Analysis of rural roads on rural poverty by the Department of Planning, using qualitative rapid assessment methods, has already been conducted in 2003.

\section{Component IV - Poverty Management Information System}

8.12 This component consists of the IT-backbone of the Poverty Monitoring System, which will be, used a tool for PMAS. The system will be built within the overall system of PIN system which is tailor-made to meet the specific needs of key decision-makers at central and local levels in Bhutan

\section{Component V - Communication/Advocacy}

8.13 The proposed communication/advocacy function of the PMS entails the dissemination of poverty-related information through some means of advocacy like National Poverty Profile Report, workshops, seminars, etc.

\section{Looking ahead}

8.14 The strengthening of the poverty monitoring and assessment system is a longterm process but is central to the effective implementation of poverty reducing programs.

8.15 The improvements of statistical capacity in the years ahead will provide a sound underpinning for future PRSP activities. 


\section{Consultative Process}

\section{Ninth Plan}

9.1 The preparation for the Ninth Plan started with a brainstorming session in August 2000 with participants from the sectoral ministries, Dzongkhag, Planning Commission and the Core Group.

9.2 This was followed by visits to the Dzongkhag by officials from the then Planning Commission Secretariat and the Core Group to discuss and explain the main elements of the Ninth Plan.

9.3 Based on the feedback from the mid-term review of the Eighth Plan, the brainstorming session and the visits to the Dzongkhag, the then Planning Commission Secretariat issued the guidelines for the preparation of the Ninth Plan in early 2001. These guidelines provided the broad national policy aims and objectives and set the general direction for the Ninth Plan based on which the sectors, Dzongkhags and the Gewogs formulated their plans. It provided clear definition and guidance on what constitutes a central plan, Dzongkhag plan and Gewog plans.

9.4 The Dzongkhag and Gewog plans were prepared after detailed discussion in the DYTs and GYTs. The DYT/GYT comprises of elected representatives of people from the Gewogs, National Assembly members representing the Dzongkhag and a member from each municipality in that Dzongkhag. The priorities and the needs are decided by DYT and GYT for Dzongkhag and Gewogs plans, respectively. The central agencies and the sectoral representatives in the Dzongkhags provided technical support and guidance to the DYT/GYT while formulating their plans.

9.5 The draft plans from the sectoral agencies, Dzongkhags and Gewogs were forwarded to the Planning Commission for review in terms of resource availability, the national aims and objectives, and the implementing capacity. While the Gewog plans were kept unchanged, the sectoral and Dzongkhag plans were sent back to the respective Dzongkhags and sectors for reprioritization and adjustments. The reprioritization exercise involved a series of consultations between the Dzongkhags and the DYT/people, the sectoral ministries, and the Planning Commission.

9.6 The final plans were endorsed by the Cabinet and approved by the National Assembly. 


\section{PRSP Process}

9.7 Since the preparation of the Ninth Plan involved an extensive consultative process with all the stakeholders, including the donor agencies during the $7^{\text {th }}$ and $8^{\text {th }}$ Round Table Meetings held in November 2000 in Thimphu and February 2003 in Geneva, respectively, the PRSP process will not be based on a separate consultation process of a similar extent.

9.8 The main agencies involved in the PRSP preparation include the then Planning Commission Secretariat (focal agency), Ministry of Finance and the key sectoral ministries. The Planning Commission Secretariat focused on the overall coordination and the crosscutting issues, Ministry of Finance was involved in the Medium Term Expenditure Framework and the sectors provided inputs on the sectoral strategies. 